\title{
Serotonin and Downstream Leucokinin Neurons Modulate Larval Turning Behavior in Drosophila
}

\author{
Satoko Okusawa, ${ }^{1}$ Hiroshi Kohsaka, ${ }^{1,2}$ and Akinao Nose ${ }^{1,2}$ \\ ${ }^{1}$ Department of Physics, Graduate School of Science, University of Tokyo, Tokyo 113-0033, Japan and ${ }^{2}$ Department of Complexity Science and Engineering, \\ Graduate School of Frontier Sciences, University of Tokyo, Chiba 277-8561, Japan
}

\begin{abstract}
Serotonin (5-HT) is known to modulate motor outputs in a variety of animal behaviors. However, the downstream neural pathways of 5-HT remain poorly understood. We studied the role of 5-HT in directional change, or turning, behavior of fruit fly (Drosophila melanogaster) larvae. We analyzed light- and touch-induced turning and found that turning is a combination of three components: bending, retreating, and rearing. Serotonin transmission suppresses rearing; when we inhibited 5-HT neurons with Shibire or Kir2.1, rearing increased without affecting the occurrence of bending or retreating. Increased rearing in the absence of 5-HT transmission often results in slower or failed turning, indicating that suppression of rearing by 5-HT is critical for successful turning. We identified a class of abdominal neurons called the abdominal LK neurons (ABLKs), which express the 5-HT1B receptor and the neuropeptide leucokinin, as downstream targets of 5-HT that are involved in the control of turning. Increased rearing was observed when neural transmission or leucokinin synthesis was inhibited in these cells. Forced activation of ABLKs also increased rearing, suggesting that an appropriate level of ABLK activity is critical for the control of turning. Calcium imaging revealed that ABLKs show periodic activation with an interval of $\sim 15 \mathrm{~s}$. The activity level of ABLKs increased and decreased in response to a 5-HT agonist and antagonist, respectively. Our results suggest that 5-HT modulates larval turning by regulating the activity level of downstream ABLK neurons and secretion of the neuropeptide leucokinin.
\end{abstract}

\section{Introduction}

Complex animal behaviors are composed of combinations of different motor patterns or components that can vary depending on the external environment or internal states. For example, mammalian quadrupedal locomotion comprises various combinations of walking, trotting, and galloping (Orlovsky et al., 1999). Neuromodulators such as neuropeptides and monoamines are known to change output motor patterns by reconfiguring the dynamics of neural circuits (Harris-Warrick and Marder, 1991; Bargmann, 2012). Neuromodulators may modulate neural circuits by changing the activity of the component neurons or the synaptic efficacy of the neural connections, or by other mechanisms. How neuromodulators change the information flow within circuits remains poorly understood, however.

Serotonin (5-HT), a monoaminergic neurotransmitter, is a well-characterized neuromodulator that plays critical roles in the regulation of a wide range of animal behaviors. In the mollusk

Received Aug. 14, 2013; revised Dec. 25, 2013; accepted Dec. $27,2013$.

Author contributions: S.O., H.K., and A.N. designed research; S.O. performed research; S.O. contributed unpublished reagents/analytic tools; S.O. analyzed data; S.O., H.K., and A.N. wrote the paper.

This work was supported by Grants-in-Aid for Scientific Research on Innovative Areas "Mesoscopic Neurocircuitry" (Grant 22115002) and "Comprehensive Brain Science Network" (Grant 22150003) of the Ministry of Education, Culture, Sports, Science, and Technology of Japan and Grant-in-Aid for Scientific Research (B) 23300114 from the Japan Society for the Promotion of Science (JSPS) (A.N.); Grant-in-Aid for Young Scientists (B) 21700344 from the JSPS (H.K.); and the Global COE Program "the Physical Sciences Frontier" (S.O.). We are grateful to T. Kitamoto, C. D. Nichols, R. A. Baines, K. Zin, J. A. Dow, B. G. Condron, P. H. Taghert, L. C. Griffith, Y. Rao, and the Bloomington Stock Center for fly stocks and reagents. We thank T. Naoi for technical assistance.

Correspondence should be addressed to Akinao Nose at the above address. E-mail: nose@k.u-tokyo.ac.jp.

DOI:10.1523/JNEUROSCI.3500-13.2014

Copyright $\odot 2014$ the authors $\quad 0270-6474 / 14 / 342544-15 \$ 15.00 / 0$
Tritonia, 5-HT converts a multifunctional circuit that can generate three distinct behaviors - escape swimming, reflexive withdrawal, and crawling - to the swim mode (Getting, 1989; Popescu and Frost, 2002). In lamprey, 5-HT modulates the swimming motor pattern in part by changing the membrane properties of spinal neurons (Harris-Warrick and Cohen, 1985; Wallén et al., 1989). In the nematode Caenorhabditis elegans, 5-HT mediates the transition from crawling to swimming and inhibits a set of crawl-specific behaviors (Vidal-Gadea et al., 2011). Little is known, however, about the downstream neurons or circuits that are critical for motor transitions. This is partly due to the global nature of 5-HT release; 5-HT, like other neuromodulators, can be secreted into the body fluid by extrasynaptic transmission in addition to being released locally by synaptic transmission. The possible global release of 5-HT often complicates the study of its downstream targets.

Larval Drosophila provides an excellent model system to study how animal behavior is affected by sensory stimuli (GomezMarin and Louis, 2012; Kane et al., 2013; Ohyama et al., 2013). Here, we study the role of 5-HT during directional change behavior (hereafter called turning behavior) in the larvae. Turning is key for escaping from noxious stimuli such as light or repulsive odor, and for exploring new territory (Rodriguez Moncalvo and Campos, 2009; Luo et al., 2010). Green et al. (1983) suggested that the turning behavior is a combination of three behavioral components: bending, retreating, and rearing (see Fig. 1A). Bending is the most commonly observed component, in which the larvae bend laterally. Retreating is peristaltic movement in a backward direction. Rearing is the movement in which the ante- 
rior half of the larval body is lifted up vertically, often with a swing motion swaying from side to side.

In this study, we first show that the turning behavior is composed of varying combinations of the three components. Then we show that 5 -HT regulates the turning behavior by specifically suppressing one of the three components, rearing. We identify a neuronal population expressing the 5-HT1B receptor and a neuropeptide, leucokinin, as the downstream targets of 5-HT. Our results suggest that $5-\mathrm{HT}$ regulates rearing by modulating the activity level of leucokinin neurons, revealing a specific neural pathway downstream of 5-HT in the modulation of animal behavior.

\section{Materials and Methods}

Fly stocks. Fly stocks were cultured at room temperature $\left(23-25^{\circ} \mathrm{C}\right)$. Crosses were raised at $22^{\circ} \mathrm{C}$ except for the crosses of RNAi experiments, which were raised at $25^{\circ} \mathrm{C}$. We used third-instar larvae [early wandering stage larvae; $132 \pm 4 \mathrm{~h}$ after egg laying (AEL) reared at $22^{\circ} \mathrm{C}$ or $108 \pm 4 \mathrm{~h}$ AEL reared at $25^{\circ} \mathrm{C}$ ] for behavioral experiments unless indicated otherwise. We used males (selected by the shape of the gonads) for all experiments, although we did not observe any obvious difference in turning behavior between males and females (data not shown).

The following fly strains were used: $w^{1118}$, Canton-S, tryptophan hydroxylase (Tph)-Gal4 (Park et al., 2006); 5-HT1A-Gal4 (Luo et al., 2012); 5-HT1B-Gal4 (Yuan et al., 2005); 5-HT2-Gal4 (Nichols, 2007); 5-HT2BGal4, 5-HT7-Gal4 (Gasque et al., 2013); c127-Gal4 (Hewes et al., 2003); UAS-Shibire $^{t s}\left(\right.$ Shi $\left.^{t s}\right)$ (Kitamoto, 2001); UAS-dTrpA1 (Hamada et al., 2008); UAS-Kir2.1 (Baines et al., 2001); UAS-mCD8::GFP (Lee and Luo, 1999); UAS-syt::GFP (Zhang et al., 2002); UAS-GCaMP3.0 (Tian et al., 2009); TH-Gal4 (Friggi-Grelin et al., 2003); tdc2-Gal4 (Cole et al., 2005); teashirt (tsh)-Gal80 (Clyne and Miesenböck, 2008); UAS-Flybow1.0, UAS-hs-mFlp5 (Hadjieconomou et al., 2011); and UAS-5-HT1A RNAi, UAS-5-HT1B RNAi, UAS-5-HT2A RNAi, UAS-5-HT2B(CG42796) RNAi, UAS-5-HT7 RNAi, UAS-Lk-RNAi, and Mi\{ET1\}5-HT1B ${ }^{M B 05181}$ (obtained from the Bloomington Stock Center). We used $w^{1118}$ flies as control animals.

Chemicals. 8-OH-DPAT (C16H25NO; Sigma) and WAY100635 (C29H38N4O6; Sigma) were used. 8-OH-DPAT is an agonist of 5-HT1A, 5-HT1B, and 5-HT7. WAY100635 is an antagonist of 5-HT1A and 5-HT1B (Tierney, 2001).

Behavioral assay. We used the GAL4-UAS system combined with $\mathrm{Shi}^{\mathrm{ts}}$ (Kitamoto, 2001), Kir2.1 (Baines et al., 2001), and TrpA1 (Hamada et al., 2008) to manipulate the transmission of specific neurons (Brand and Perrimon, 1993). All experiments were performed at $32^{\circ} \mathrm{C}$ unless noted otherwise. In a light-induced directional change assay, turning was evoked by strong blue light with an $\mathrm{Hg}$ light source (460-496 nm, 850 $\mu \mathrm{W} / \mathrm{mm}^{2}$ ) under stereoscopic microscopy (SZX16; Olympus). Hg light was focused to stimulate a narrow area that covered the upper half of the larval body. For the experiments at $32^{\circ} \mathrm{C}$, agar plates were maintained at $32^{\circ} \mathrm{C}$ with a heat plate (MATS-55SF; Tokai Hit). Third instar larvae were picked up from a vial and rinsed carefully. Larvae were then set on an agar plate for a $5 \mathrm{~min}$ acclimation period. We applied the light to freely locomoting larvae by opening the shutter of a blue light path. Stimulated larvae stopped peristalsis movement and underwent a directional change for an avoidance behavior. When larvae completed a directional change and restarted the peristalsis, we stopped the light stimulation. We defined this process as one event of the behavioral assay. 8-OH-DPAT at a concentration of $5 \mathrm{~mm}$ in yeast paste was given to the larvae $48 \mathrm{~h}$ before the behavioral assay.

To measure larval responses to a mechanical stimulus, we put coarse paper on the agar plate and observed larval behavior when they hit and entered the paper section at a perpendicular angle during locomotion.

We analyzed five events per each of 7-25 larvae for all behavioral assays mentioned above. The events were recorded using a CCD camera (XCDV60; Sony) at 15 frames per second. By watching a video of each event, we manually enumerated the three behavioral components (bending, retreating, and rearing) in each event. We defined bending as a head swing with the angle between the axis of the anterior part of the larva and that of the posterior body at $>30$ degrees. We counted a larva bending to the right and left in succession as two bendings. We defined retreating as the occurrence of partial or complete backward peristalsis, and rearing as a complete vertical lifting of the anterior part of the body from the surface of the agar plate. Occasionally, larvae finish rearing by undergoing bending. In these cases, the behavior was counted for both rearing and bending. The failure rate of turning was defined as the number of failed turnings divided by the total number of light or mechanical stimulations. A failed turning refers to the initiation of peristalsis before the larva changed direction in the case of light stimulation, and initiation of peristalsis on the paper in the case of mechanical stimulation. Behavioral responses to five stimulations were analyzed for each larva. Rearing incidence in free locomoting larvae was measured by video recordings of the larvae undergoing locomotion on the agar plate at $32^{\circ} \mathrm{C}$. We analyzed five spontaneous turnings for each larva. The rolling behavior was induced by pinching the body wall of a larva with tweezers. We measured the speed of larval forward locomotion by measuring the duration of each peristaltic wave in the video recordings of freely locomoting larvae at 30 frames per second.

Immunostaining and microscopy. For immunostaining of the ventral nerve cord (VNC), we dissected and pinned each larva on a silicone plate to expose the brain and VNC. The preparation was then fixed and stained as described previously (Nose et al., 1997). We used rabbit anti-GFP (Invitrogen; 1:1000), mouse anti-GFP (Sigma; 1:100), rabbit anti-5-HT (Sigma; 1:200), rabbit anti-leucokinin (Al-Anzi et al., 2010), rabbit antileucokinin receptor (Radford et al., 2002), rat anti-elav (Developmental Studies Hybridoma Bank), and mouse anti-V5 (Invitrogen; 1:500) as primary antibodies. We used goat anti-rabbit IgG conjugated with Alexa 488 (Invitrogen; 1:300), goat anti-mouse IgG conjugated with Alexa 488 (Invitrogen; 1:300), goat anti-rabbit IgG conjugated with Cy3 (Invitrogen; 1:300), and goat anti-mouse IgG conjugated with Alexa 555 (Invitrogen; 1:300) as secondary antibodies. Confocal images were taken using a $60 \times$ objective lens with an Olympus FV-1000 confocal microscopy.

Calcium imaging. We dissected third instar wandering larvae and imaged them in $\mathrm{Ca}^{2+}$-free insect normal saline (5 mM HEPES-NaOH, 140 $\mathrm{mm} \mathrm{NaCl}, 2 \mathrm{~mm} 6 \mathrm{~mm} \mathrm{KCl}, \mathrm{MgCl}_{2}, 36 \mathrm{~mm}$ sucrose, $\mathrm{pH}$ 7.1) to avoid movements of the muscles.We imaged the fluorescence change of GCaMP3 in the VNC using an upright Axioskop2 FS microscope (Zeiss) equipped with an EM CCD camera (iXon) with a $40 \times$ water-immersion objective lens, at a rate of $10 \mathrm{~Hz}$. For quantitative analysis of the temporal change of the fluorescence signal, regions of interest (ROIs) were drawn around cell bodies or the terminal plexus. For drug administration experiments, collagenase type IV (Sigma-Aldrich) at a concentration of 0.5 $\mathrm{mg} / \mathrm{ml}$ was applied for $30 \mathrm{~s}$ to remove the glial sheath surrounding the VNC and facilitate penetration of the drug within the VNC. Three minutes after washing out the collagenase, imaging was performed for $\sim 100$ $s$ in the absence of the drug. Then the saline containing the drug $(8-\mathrm{OH}-$ DPAT or WAY100635) was added to the bath at a final concentration of $5 \mathrm{~mm}$, and imaging was performed for another $\sim 100 \mathrm{~s}$. Two ROIs (around cell bodies of the abdominal LK neurons) were analyzed before and after drug administration in each larva, and their average fluorescent signal in each frame was used in data analysis.

We smoothed the fluorescent signal by averaging the intensity over 10 frames. To correct for the baseline decline due to photobleaching, we defined the baseline fluorescence $F_{0}(t)$ as the minimum signal from $t-$ 10 to $t+10 \mathrm{~s}$, and normalized the fluorescent signal as $\Delta F / F(\%)=$ $100 *\left[F(t)-F_{0}(t)\right] / F_{0}$. To investigate the effects of drugs, we counted the number of frames in which the fluorescent signal was above a certain threshold level $(\Delta F / F=0.5,1,2,4,6$, and $8 \%)$ before and after drug application, and then used the ratio between before and after drug application as the measure for the change in activity level. Similarly, we counted the number of peaks in which the $\Delta F / F$ was above $4 \%$ and used the ratio between before and after drug application as a measure for the change in the frequency of activity.

Statistical analysis. For pairwise comparisons, a Welch's $t$ test was used. We performed a one-way ANOVA with Tukey's post hoc test and a twoway ANOVA for comparisons among the relevant groups. Data are presented as means \pm SEM. 
A blue light

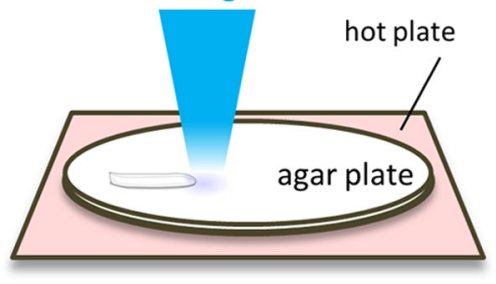

bending

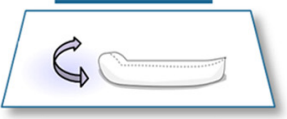

retreating

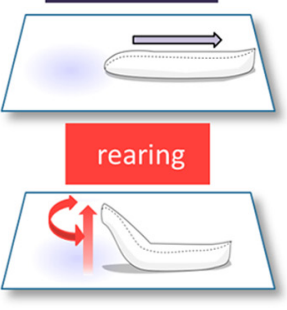

$A \longleftrightarrow P$

B

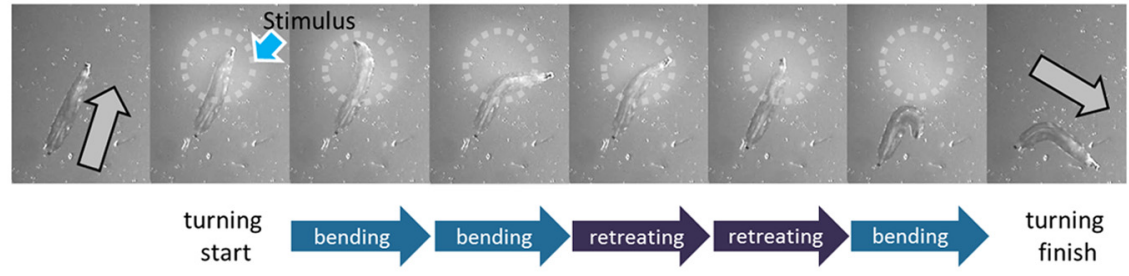

C

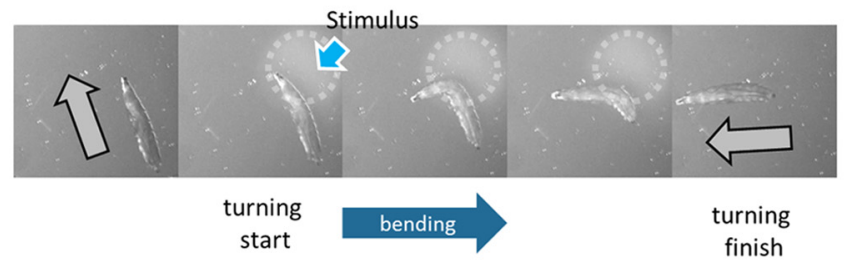

D
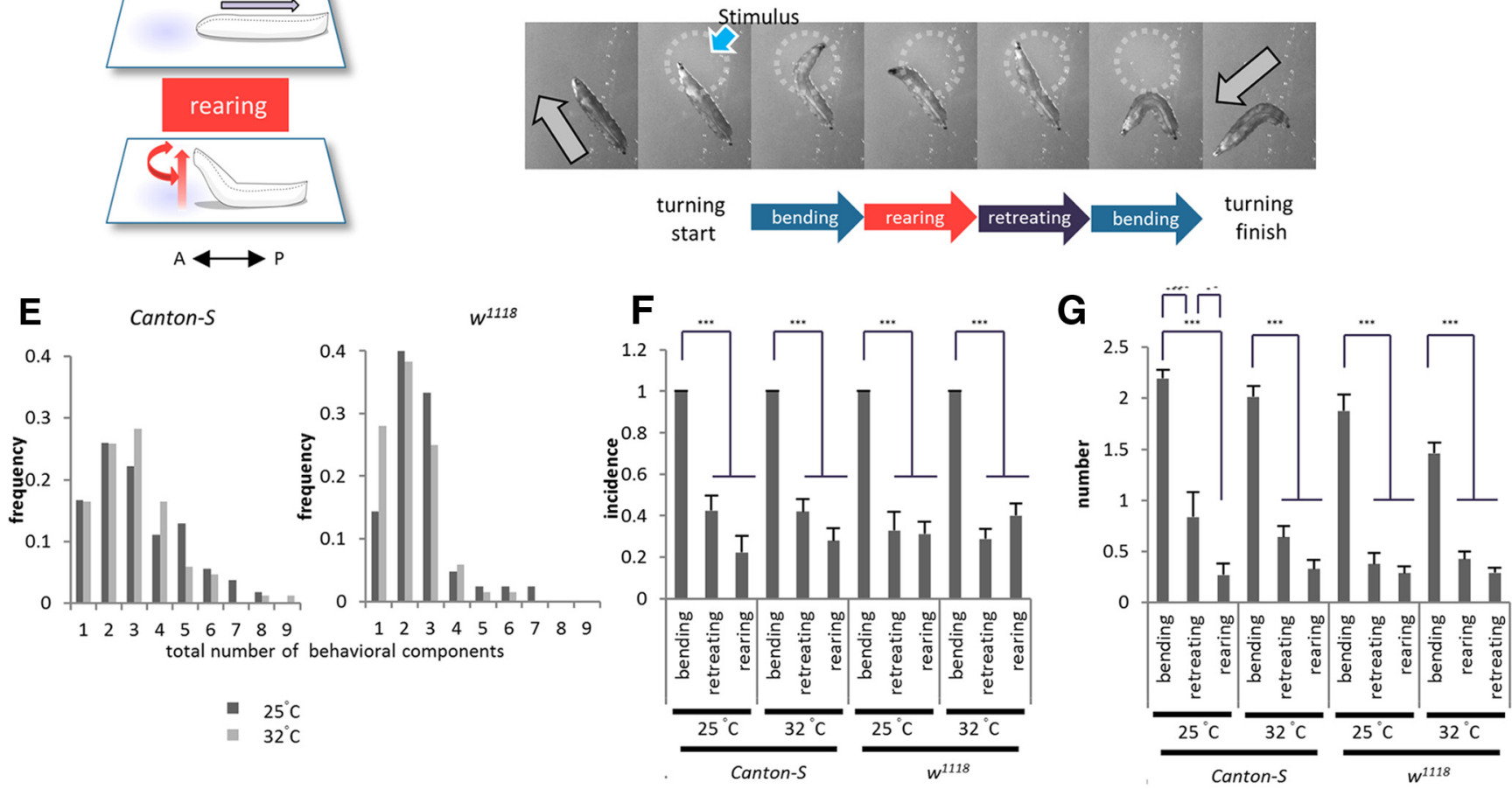

Figure 1. Larval directional change behavior consists of three components: bending, retreating, and rearing. $A$, Schematic of the behavioral assay and three components of the directional change behavior. The anterior-posterior (A-P) axis of a larva is shown by a double-headed arrow in this and subsequent figures. $\boldsymbol{B}-\boldsymbol{D}$, Examples of the directional change in wild-type (Canton-S) larvae. Snap shots of each turning event are shown. The circles enclosed by white dashed lines indicate the region of the light stimulus. Gray arrows indicate larval direction before and after directional change in this and subsequent figures. $\boldsymbol{E}$, Histograms of the total number of behavioral components in each event. Results were obtained from 54 turning events in 11 larvae at $25^{\circ} \mathrm{C}$ and 84 events in 16 larvae at $32^{\circ} \mathrm{C}$ (Canton-S, left), and 42 events in 9 larvae at $25^{\circ} \mathrm{C}$ and 68 events of 13 larvae at $32^{\circ} \mathrm{C}\left(w^{1118}\right.$, right). $\boldsymbol{F}$, Incidence of each component (bending, retreating, and rearing) included in a turning event. $n=13-16$. G, Average number of each component included in a turning event. $n=13-16 .{ }^{*} p<0.05 ;{ }^{* * *} p<0.001$ (Tukey-Kramer post hoc test).

\section{Results}

Larval turning consists of variable combinations of bending, retreating, and rearing

Drosophila larvae exposed to blue light show turning behavior to escape from the stimulation (Xiang et al., 2010). To efficiently trigger turning behavior, we applied light focally to the anterior part of each crawling larva under a stereoscopic microscope (Fig. 1A; see Materials and methods). We first quantified the number of behavioral components [as defined by Green et al. (1983)] during turning in third-instar (early wandering stage) larvae. Our analyses of control larvae (Canton-S and $w^{1118}$ ) showed that each turning response consists of a combination of three behavioral components: bending, retreating, and rearing. Three examples are shown in Figure $1 B-D$ and Movie 1. In the first example (Fig. $1 B$ ), two each of bending and retreating movements were observed before the turn-

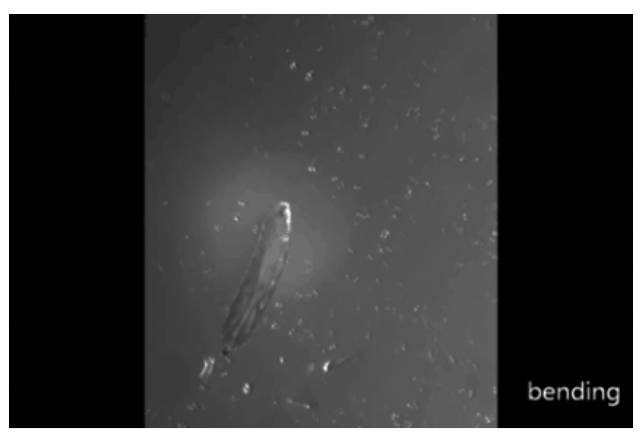

Movie 1. Directional change behavior of Canton-S larvae. This movie is related to Figure 1. The speed of the movie is $0.5 \times$ the raw data. 
A

$\mathbf{B}$
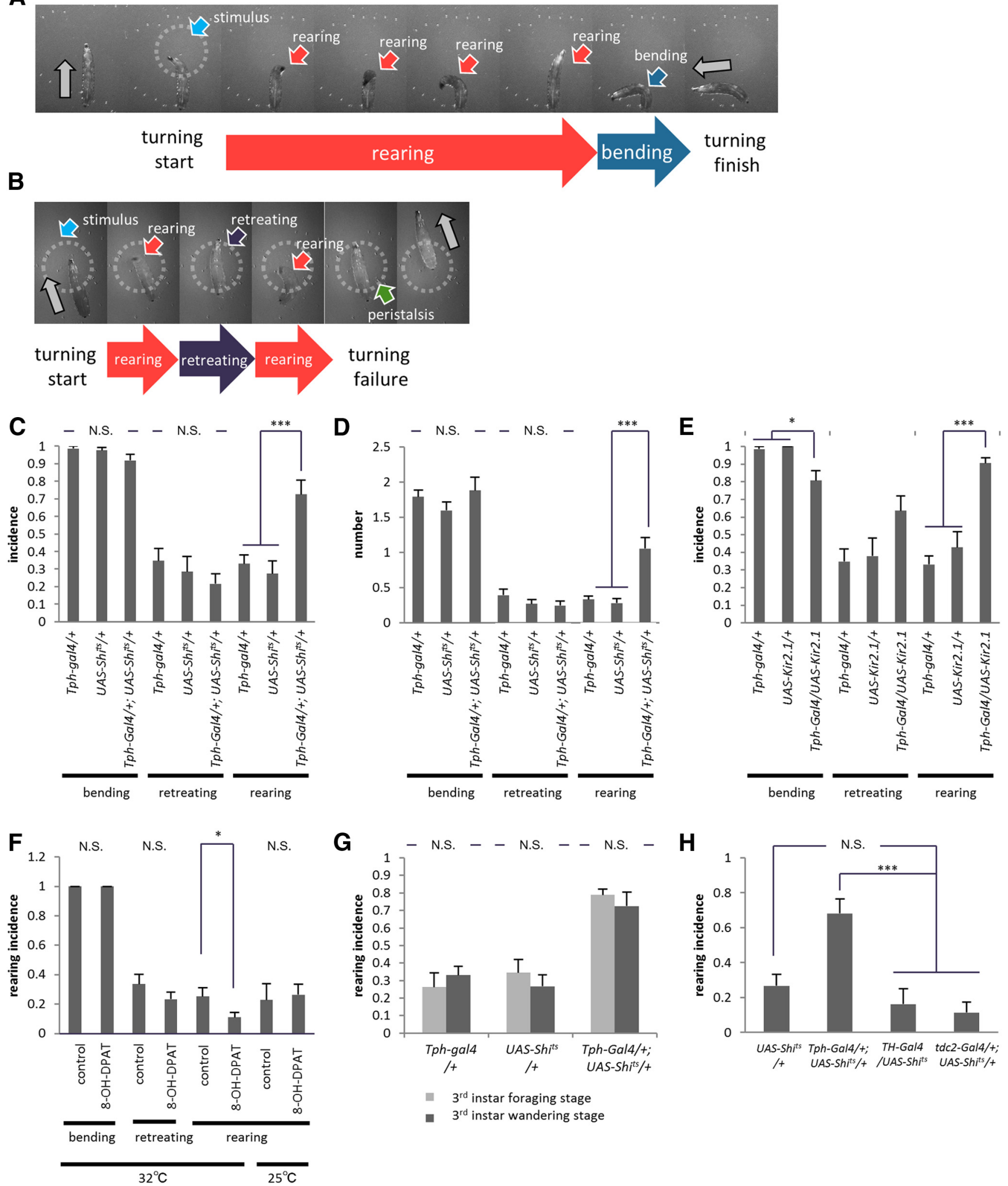

Figure2. Blocking 5-HT transmission increases rearing during directional change behavior. $A-E$, Rearing is increased in Tph-Gal4/+; UAS-Shits/+ $(\boldsymbol{A}, C, D)$ and Tph-Gal4/UAS-Kir2.1 (B, E) larvae. $\boldsymbol{A}, \boldsymbol{B}$, Examples of increased rearing during turning. $\boldsymbol{C}-\boldsymbol{E}$, Quantitative analyses showing an increased incidence $(\boldsymbol{C}, \boldsymbol{E})$ and the average number $(\boldsymbol{D})$ of rearing events $(n=11-15)$. $\boldsymbol{F}$, Decrease of rearing incidence upon administration of a $5-\mathrm{HT}$ agonist, $8-0 \mathrm{H}-\mathrm{DPAT}$, at $32^{\circ} \mathrm{C}(n=24-25)$ and $25^{\circ} \mathrm{C}(n=8-11)$. G, Rearing incidence and effects of 5-HT inhibition are similar between the foraging $\left(108 \pm 4 \mathrm{~h} \mathrm{AEL}\right.$ reared at $\left.22^{\circ} \mathrm{C}\right)$ and wandering stages of the third instar $(n=10-14) . \boldsymbol{H}$, Inhibition of dopaminergic and octopaminergic/tyraminergic neurons in TH-Gal4/UAS-Shit ${ }^{\mathrm{t}}$ and tdc2-Gal4/+;UAS-Shits $/+$ larvae, respectively, has no effect on rearing $(n=7-14)$. All experiments were performed at $32^{\circ}$ C unless noted otherwise. ${ }^{*} p<0.05 ;{ }^{* * *} p<0.001[$ Tukey-Kramer post hoc test $(\boldsymbol{C}-\boldsymbol{E}, \boldsymbol{H})$ or Welch's test $(\boldsymbol{F}, \boldsymbol{G})]$. N.S., No significant statistical difference. 


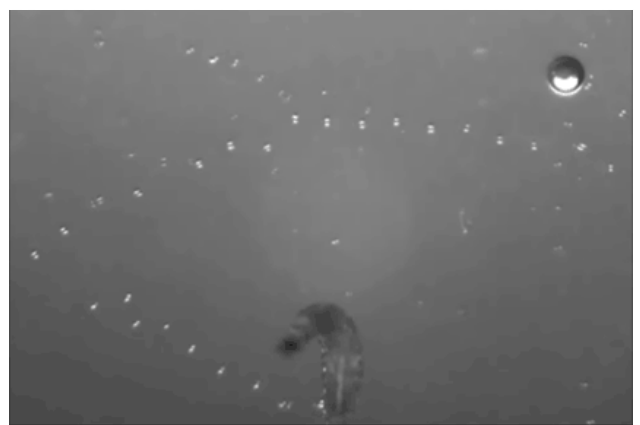

Movie 2. Directional change behavior of control and Tph-Gal4/UAS-Shibire ${ }^{t s}$ larvae induced by a light stimulus. This movie is related to Figure 2 .

ing was completed by the third bending. In the second example (Fig. 1C), the larva completed the turning by a single bending. In the last example (Fig. 1D), the larva exhibited a complex response that included all three behavioral components.

To quantitatively characterize the composition of the turning behavior, we measured three parameters as described below. First, we counted the total number of behavioral components included in each turning event (for example, in the three examples above, the total numbers are five, one, and four, respectively). This number showed a wide distribution (Fig. 1E). Next, we studied the incidence of each component in each turning event. Analyses of the incidences indicate that at least one bending occurred in each turning event (Fig. $1 F$ ). In contrast, retreating and rearing were observed in only $\sim 30 \%$ of the events. Finally, we studied the total number of each component in each turning event and found that, on average, 1.5-2.2 bending, $\sim 0.5$ retreating, and $\sim 0.3$ rearing movements occurred per event (Fig. $1 G)$. These results show that bending is an essential component of turning and occurs at least once during the turning event, whereas retreating and rearing are dispensable and occur more infrequently $\left(p<0.001\right.$; Fig. $1 F$, Canton $-S$ at $25^{\circ} \mathrm{C}, F_{(2,27)}=35.8$; at $32^{\circ} \mathrm{C}, F_{(2,42)}=56.3 ; w^{1118}$ at $25^{\circ} \mathrm{C}, F_{(2,21)}=31.4$; at $32^{\circ} \mathrm{C}, F_{(2,33)}=$ 62.6; Fig. $1 G$, Canton- $S$ at $25^{\circ} \mathrm{C}, F_{(2,30)}=37.4$; at $32^{\circ} \mathrm{C}, F_{(2,45)}=79.2$; $w^{1118}$ at $25^{\circ} \mathrm{C}, F_{(2,23)}=56.6$; at $32^{\circ} \mathrm{C}, F_{(2,36)}=65.9 ; n=13-16$ animals per genotype, one-way ANOVA). Similar results were obtained when the assay was performed at 25 or $32^{\circ} \mathrm{C}$ (Fig. $1 \mathrm{~F}, \mathrm{G}$ ) and in the two strains we used as controls (Canton-S and $w^{1118}$ ). Together, our results indicate that larval directional change behavior is generated by a variable combination of bending, retreating, and rearing, with bending being the essential and most frequent component.

\section{Inhibition of 5-HT neurons increases rearing, but not bending or retreating, during turning behavior}

Next we asked whether 5-HT plays some role in the control of turning behavior. For this, we first studied the effects of blocking the transmission of 5-HT neurons using the temperaturesensitive dynamin protein, Shibire ${ }^{\text {ts }}\left(\mathrm{Shi}^{\mathrm{ts}}\right)$ (Kitamoto, 2001). We used Tph-Gal4 to drive Shi ${ }^{\text {ts }}$ expression in 5-HT neurons. This Gal4 line drives expression in most of 5-HT-expressing neurons and weakly in a few 5-HT-negative neurons in the VNC (Chen and Condron, 2008; Huser et al., 2012). We found that temporal inhibition of Tph-Gal4 neurons increased the incidence of rearing without affecting that of bending and retreating (Fig. $2 A$, Movie 2 ). Whereas rearing was seen in only $\sim 30 \%$ of the turning events in the control larvae, it was observed in $\sim 70 \%$ of the events when transmission of 5-HT neurons was inhibited $\left(F_{(2,37)}=12.9, p<0.001, n=11-15\right.$ animals per genotype, one-way ANOVA; Fig. 2C). The average number of rearing behaviors that occurred in each event also increased $\left(F_{(2,36)}=16.3\right.$, $p<0.001, n=11-15$ animals per genotype, one-way ANOVA; Fig. $2 D)$. In contrast, incidence and average number of bending or retreating did not change $\left(p>0.05\right.$; Fig. $2 C$, bending, $F_{(2,37)}=$ 2.4; retreating, $F_{(2,37)}=0.9$; Fig. $2 D$, bending, $F_{(2,36)}=1.0$; retreating, $F_{(2,36)}=1.3 ; n=11-15$ animals per genotype, one-way ANOVA). Thus, temporal inhibition of Tph-Gal4 neurons specifically increased the incidence of rearing without affecting that of bending and retreating. An abnormal phenotype (Fig. 2B) and a specific increase in rearing was also observed when the transmission of Tph-Gal4 neurons was blocked by expression of Kir2.1 at $32^{\circ} \mathrm{C}\left(F_{(2,35)}=33.3, p<0.001, n=11-15\right.$ animals per genotype, one-way ANOVA; Fig. $2 E$ ). Sitaraman et al. (2008) showed that the level of 5-HT in the adult heads of $w^{1118}$ is only $30 \%$ of that in Canton-S. However, there was no statistically significant difference in the incidence and total number of rearing between $w^{1118}$ and Canton-S (Fig. $1 F, p>0.05, F_{(1,45)}=0.04, F_{(1,45)}=1.9$; Fig. $1 G, p>0.05, F_{(1,44)}=0.01, F_{(1,44)}=0.1 ; n=11-15$ animals per genotype, two-way ANOVA). Thus, this level of decrease in 5-HT expression appears to only have limited impacts on the regulation of rearing. Inhibition of 5-HT neurons had no obvious effects on other larval behaviors including rolling (data not shown) and forward peristaltic locomotion (duration of a single forward peristalsis, $0.59 \pm 0.01 \mathrm{~s}$ in Tph-Gal4/+; UAS-Shits $/+$ compared to $0.54 \pm 0.02$ and $0.55 \pm 0.02 \mathrm{~s}$ in Tph-Gal4/+ and UAS-Shits $/+$, respectively; $F_{(2,17)}=1.3, p>0.05, n=6-10$ animals per genotype, one-way ANOVA followed by Tukey-Kramer test).

We next investigated what happens to the turning behavior when 5-HT neurons are activated. For this purpose, we initially tried to use the Drosophila temperature-sensitive cation channel dTrpA1 (UAS-TrpA1; Hamada et al., 2008). However, when 5-HT neurons were activated by the dTrpA1 channel, larval locomotion was strongly compromised, hampering the assay of the directional change. Therefore, we next studied the effects of a 5-HT agonist, 8-OH-DPAT, which increases the levels of serotonin signaling in the larval body by acting specifically on the 5-HT receptors 5-HT1A, 5-HT1B, and 5-HT7 (Tierney, 2001; Johnson et al., 2009). We found that oral administration of 8-OH-DPAT significantly reduced the incidence of rearing during the larval turning assay $\left(t_{(36)}=2.1, p<0.05, n=24-25\right.$ animals per group, Welch's test; Fig. $2 F$ ). These results indicate that the level of 5-HT is critical for the regulation of rearing behavior.

A previous study reported that light reactivity changes between the foraging and wandering stages of third instar larvae and that this transition in light sensitivity is regulated by 5 -HT neurons (Rodriguez Moncalvo and Campos, 2009). In our experimental system, however, the larvae responded to light to a similar degree at both developmental stages, possibly because stronger light was applied in our assay $\left(t_{(23)}=1.4, p>0.05, n=14\right.$ animals per genotype, Welch's test; Figure $2 G)$. Furthermore, an increase in rearing was observed at both the foraging and wandering stages when 5-HT neurons were inhibited. Thus, an increase in rearing caused by 5 -HT inhibition appears to be independent of a role for 5-HT in developmental changes in light reactivity. We also questioned whether rearing could be induced by inhibition of other biogenic amines. We used TH-Gal4 and $t d c 2-G a l 4$ lines to drive Shi ${ }^{\text {ts }}$ expression in dopamine neurons and octopamine/tyramine neurons, respectively. An increase in rearing incidence was not observed ( $p>0.05, n=7-14$ animals per genotype, Tukey-Kramer test; Fig. $2 H$ ), indicating that 5-HT plays a specific role among the biogenic amines in the regulation of rearing. 

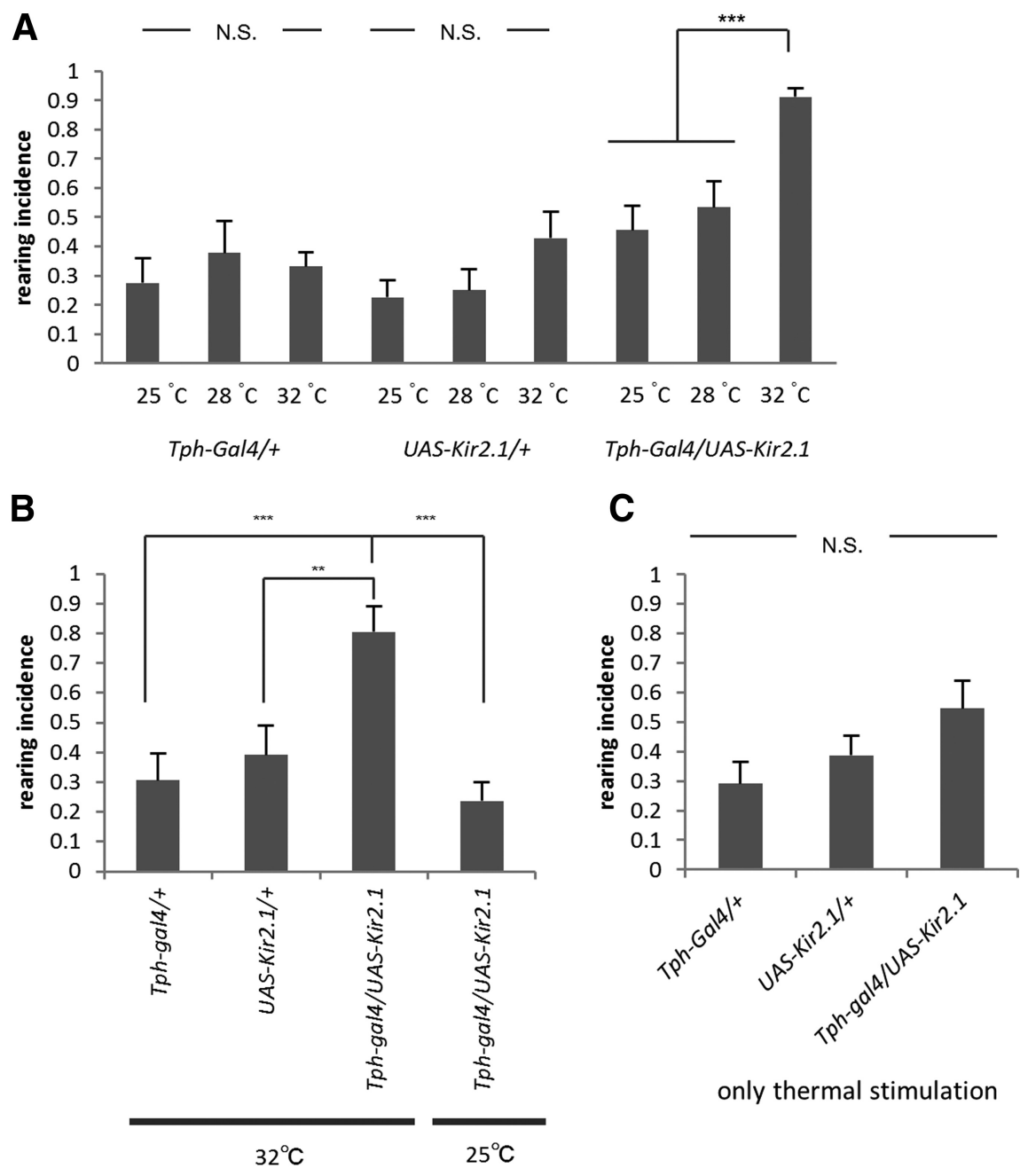

mechanical stimuli

Figure 3. Control of rearing by $5-\mathrm{HT}$ transmission is temperature dependent and is also involved in mechanically induced turning. A, Temperature dependence. Incidence of rearing during light-induced turning in control and Tph-Gal4/UAS-Kir2.1 larvae at different temperatures $\left(25,28\right.$, and $\left.32^{\circ} \mathrm{C}\right)$ is shown. The effects of the inhibition of 5 - $\mathrm{HT}$ transmission are temperature dependent $(n=8-11), B, 5-H T$ transmission is required to suppress rearing during mechanostimulus-induced turning at $32^{\circ} \mathrm{C}(n=8-11)$. C, Rearing incidence of Tph-Gal4/UAS-Kir2. 1 larvae when only thermal stimulation (without light stimulation) was applied at $32^{\circ} \mathrm{C}$ $(n=8-10) .{ }^{* *} p<0.01 ;{ }^{* * *} p<0.001$ (Tukey-Kramer post hoc test). N.S., No significant statistical difference.

\section{5-HT transmission is required to suppress rearing when larvae receive multiple sensory inputs}

The experiments described above suggest that 5-HT inhibits rearing during light-induced turning behavior. However, since the behavioral assays were performed at a high temperature $\left(32^{\circ} \mathrm{C}\right)$ to activate temperature-sensitive $\mathrm{Shi}^{\text {ts }}$, thermal stimuli could be a factor affecting the action of 5-HT. We therefore used UASKir2.1 to inhibit 5-HT neurons at different temperatures and found that the effect of 5 -HT inhibition was indeed temperature dependent. As shown in Figure 3A, inhibition of 5-HT neurons had no effect on the incidence of rearing at 25 and $28^{\circ} \mathrm{C}$ compared to the incidence at $32^{\circ} \mathrm{C}\left(F_{(2,36)}=14.2, p<0.001, n=8-11\right.$ animals per genotype, one-way ANOVA; Fig. $3 A$ ). These results point to the importance of temperature in the control of rearing by 5 -HT neurons. However, no increase in rearing was induced by inhibition of 5-HT neurons when thermal stimulation alone (without light stimulation) was applied to the larvae $\left(F_{(2,23)}=\right.$ $2.5, p>0.05, n=8-10$ animals per genotype, one-way ANOVA; Fig. $3 C$ ). These results suggest that $5-\mathrm{HT}$ transmission is required to suppress rearing when larvae receive both light and thermal stimuli. Temperature dependence was also seen for the rearing phenotype when 5 -HT signaling was increased by oral administration of an agonist, 8-OH-DPAT: no decrease in rearing was observed when the behavioral assay was performed at $25^{\circ} \mathrm{C}\left(t_{(10)}=0.3\right.$, $p>0.05, n=8-11$ animals per group, Welch's test; Fig. $2 F$ ).

We next asked whether 5-HT transmission is required to suppress rearing when sensory stimuli other than light are used to induce turning. For this purpose, we used noxious mechanical stimuli as a trigger for directional change. We laid coarse paper in the path of larval locomotion. When the larvae hit and crawled on the paper, they exhibited a turning response as was observed upon light stimuli (Movie 3). Rearing incidence increased when 5-HT neurons were inhibited during this assay $\left(F_{(2,32)}=9.1, p<0.01, n=\right.$ $8-11$ animals per genotype, one-way ANOVA; Fig. 3B). Thus, 5-HT transmission regulates rearing during larval turning induced by multiple types of triggers. As was the case with light-induced turning, the regulation of rearing by $5-\mathrm{HT}$ transmission was temperature dependent: the increase in rearing was not observed at $25^{\circ} \mathrm{C}$ (incidence, $32^{\circ} \mathrm{C}, 0.80 \pm 0.08 ; 25^{\circ} \mathrm{C}$, $0.24 \pm 0.06 ; p<0.001, n=8-11$ animals per genotype, Tukey-Kramer test; Fig. $3 B)$.

\section{5-HT-mediated suppression of rearing} is required for successful turning

We next investigated the role of 5-HTmediated suppression of rearing. To address this question, we evaluated how increased rearing in the absence of 5-HT transmission affects larval turning. First, we measured the duration of the entire directional change process evoked by light or mechanosensation. The duration of the behavior was greatly increased upon 5-HT inhibition when either the light or mechanical stimulation was used as a trigger (light stimuli, $F_{(2,29)}=37.7$; mechanical stimuli, $F_{(2,26)}=7.7 ; p<0.001, n=8-14$ animals per genotype, one-way ANOVA; Figure $4 A, B)$. Thus, in the absence of 5-HT transmission, the directional change process takes longer. There was a close correlation between the number of rearing events and the duration of the turning behavior, suggesting that the increase in rearing is the cause of the longer duration of turning (Fig. 4C). We next studied failure rates of the directional change and found that in the absence of 5-HT transmission, turning often failed to be completed (Fig. $2 \mathrm{~B}$ ). In the case of turning in response to light, failed turning results in the reinitiation of peristalsis before the larvae change direction. In the case of turning in response to rough paper, a failed turning results in peristalsis on the paper. In either case, the larvae failed to avoid the noxious stimuli by turning (light stimuli, $F_{(2,29)}=37.5, p<0.001$; mechanical stimuli, $F_{(2,26)}=3.6, p<0.05 ; n=8-14$ animals per genotype, one-way 


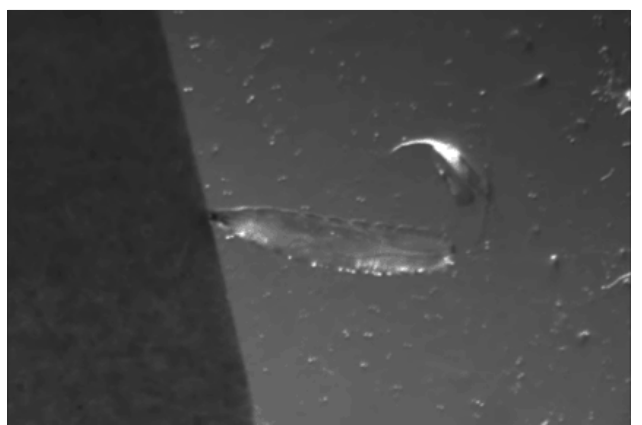

Movie 3. Directional change behavior of control and Tph-Gal4/UAS-Kir2.1 larvae induced by a mechanostimulus. This movie is related to Figures 3 and 4.

ANOVA; Fig. 4D,E; Movie 3). Again, there was a close correlation between the number of rearing events and success/failure of the turning (light stimuli, $t_{(35)}=3.9, p<0.001$; mechanical stimuli, $t_{(38)}=2.4, p<0.05 ; n>14$ events per group, Welch's test; Fig. $4 F)$. These results suggest that inhibition of rearing by $5-\mathrm{HT}$ is required for prompt and successful turning.

\section{Rearing is regulated by $5-\mathrm{HT}$ neurons in the ventral nerve cord}

In the larval CNS, 5-HT is expressed in 10 cells in each brain hemisphere, 16 cells in the suboesophageal ganglion (SOG), and in two pairs of neurons in each neuromere in the VNC except in A8 and T1, where one and three pairs of neurons are present, respectively (Vallés and White, 1988; Chen and Condron, 2008; Huser et al., 2012). We next used tsh-Gal80, which suppresses Gal4 action in the VNC, to determine which of the neuronal populations is involved in the control of rearing (Clyne and Miesenböck, 2008). We first confirmed that tsh-Gal80 efficiently suppresses the Tph-Gal4-driven expression in the VNC, but not in the brain or SOG, by using UAS- $m C D 8:: G F P$ as a reporter (Fig. $5 A, B)$. Next we measured rearing incidence in Tph-Gal4/+; $U A S-S h i^{t s} /+$ larvae with or without the tsh-Gal80 transgene. The increase in rearing by expression of Shi ${ }^{\text {ts }}$ by $T p h$-Gal4 was largely rescued by the $t$ sh-Gal80 transgene $\left(F_{(2,28)}=15.1, p<0.001, n=\right.$ 9-14 animals per genotype, one-way ANOVA; $p<0.01$, TukeyKramer post hoc test; Fig. $5 C$ ). This observation indicates that 5 -HT neurons in the VNC, not the brain, are involved in the regulation of rearing.

To study the distribution of synaptic terminals of the 5-HT neurons in the VNC, we expressed a presynaptic marker, Synaptogagmin (Syt)-GFP, in these cells. Consistent with a previous study (Sykes and Condron, 2005), Syt-GFP-positive putative presynaptic sites of 5-HT neurons were widely distributed in the VNC (Fig. 5D). This result suggests that 5-HT is released broadly in the VNC.

\section{5-HT1B receptors are involved in the control of rearing}

We next investigated the downstream neural pathway of 5-HT involved in the regulation of rearing. In Drosophila, five 5-HT receptors, 5-HT1A, 5-HT1B, 5-HT2A, 5-HT2B, and 5-HT7, have been identified. To determine which of the receptors are involved, we first used Gal4 lines specific to the neurons that express each receptor (Yuan et al., 2005; Nichols, 2007; Luo et al., 2012; Gasque et al., 2013) to study whether blocking their transmission leads to the same phenotype as when 5-HT neurons are inhibited. We found that expression of Shi ${ }^{\text {ts }}$ by $5-H T 1 B-G a l 4$, but not 5-HT1A-Gal4, 5-HT2A-Gal4, 5-HT2B-Gal4, or 5-HT7Gal4, increased rearing during light-induced turning $\left(F_{(7,63)}=\right.$
5.2, $p<0.001, n=7-14$ animals per genotype, one-way ANOVA; Fig. 6A). Thus, transmission by cells expressing the 5-HT1B receptor is required for the regulation of rearing. We also used tsh-Gal80 to suppress 5-HT1B-Gal4-driven expression in the VNC and found that the increase in rearing was rescued $\left(F_{(2,31)}=\right.$ 12.8, $p<0.001, n=9-10$ animals per genotype, one-way ANOVA; $p<0.001$, Tukey-Kramer post hoc test; Fig. $6 I$ ). Thus, 5 -HT1B neurons in the VNC are involved in the regulation of rearing.

Further support for the role of 5-HT1B receptors was obtained through analyses of the mutants. A transposon-mediated mutation of 5-HT1B, Mi\{ET1\}5-HT1B ${ }^{M B 05181}$, is a hypomorphic allele that produces a reduced level of mRNA (Johnson et al., 2011). An increase in rearing incidence was seen in the mutant larvae $\left(t_{(22)}=3.2\right.$, $p<0.01, n=10-11$ animals per genotype, Welch's test; Fig. $6 B)$. An increase in rearing was also seen when shRNA of 5-HT1B, but not 5-HT1A, 5-HT2A, 5-HT2B, or 5-HT7, was expressed in 5-HT1BGal4 neurons $\left(F_{(8,77)}=5.7, p<0.001, n=9-16\right.$ animals per genotype, one-way ANOVA; Fig. $6 C$ ). These data indicate that the 5 -HT1B receptor is involved in the regulation of rearing. The increase in rearing in the larvae expressing shRNA of 5-HT1B was not seen when the behavioral assay was performed at $25^{\circ} \mathrm{C}$ (incidence, $0.71 \pm 0.04$ at $32^{\circ} \mathrm{C}, 0.36 \pm 0.03$ at $25^{\circ} \mathrm{C} ; p<0.01, n=9-16$ animals per genotype, Tukey-Kramer test; Fig. $6 \mathrm{C}$ ). Thus, the regulation of rearing by the $5-\mathrm{HT} 1 \mathrm{~B}$ receptor is temperature dependent, as was the case for 5 -HT.

We studied the morphology of 5-HT1B-Gal4 neurons by expressing mCD8::GFP. As shown in Figure 6D, 5-HT1B-Gal4 was expressed in three distinct cell types. First, expression was seen in a single neuron per hemineuromere of segments A1-A7 (Fig. $6 D^{\prime}$, green cells), which showed a characteristic morphology with two axons, one projecting along the longitudinal tract and terminating at the posterior end of the neuropile (terminal plexus; Fig. $6 E, H)$ and the other projecting to the periphery and terminating on muscle 8 (Fig. $6 F$ ). As will be described below, we identified these neurons as leucokinin-positive the abdominal LK neurons (ABLKs) and as being involved in the regulation of rearing. The other cell groups that expressed $5-H T 1 B-G a l 4$ were a single interneuron per hemisegment located more medially (Fig. $6 D^{\prime}$, orange cells, $G$ ) and cells at the midline $\left(D^{\prime}\right.$, gray cells), which are Elav negative and thus are likely to be glia.

\section{Leucokinin transmission by $5 \mathrm{HT} 1 \mathrm{~B}$-positive $\mathrm{ABLK}$ neurons is involved in the control of rearing}

Leucokinin, a neuropeptide, is specifically expressed in the VNC in a single neuron in each abdominal hemisegment (de Haro et al., 2010). A total of 14 cells are present (in A1 to A7) and are called ABLK neurons. The axons of these neurons project to two distinct destinations: one within the CNS to the terminal plexus and the other out to the periphery terminating on lateral muscle 8 (Cantera and Nässel, 1992; Landgraf et al., 2003; Santos et al., 2007; de Haro et al., 2010). The characteristic morphology closely resembles that of a population of 5-HT1B-expressing neurons described above, suggesting the possibility that they may be the same cells. We confirmed that this is the case by double staining for leucokinin (with an antileucokinin antibody) and GFP expressed in 5-HT1B-Gal4 neurons. The two signals colocalized in the same neurons in the VNC, indicating that this population of $5-H T 1 B$-expressing neurons comprises leucokinin-positive ABLKs (Fig. $7 A, B$ ).

We next asked whether this population of $5-H T 1 B$-expressing neurons is involved in the regulation of rearing. For this purpose, we used a Gal4 line specific to leucokinin neurons, c127-Gal4. Expression of Shi ${ }^{\text {ts }}$ by $c 127-$ Gal4 increased rearing $\left(F_{(2,44)}=6.8\right.$, 
A

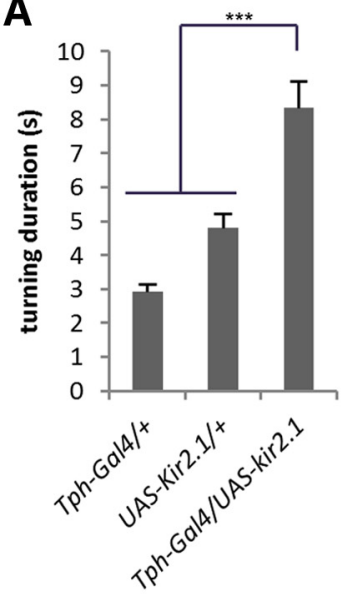

light stimuli
B

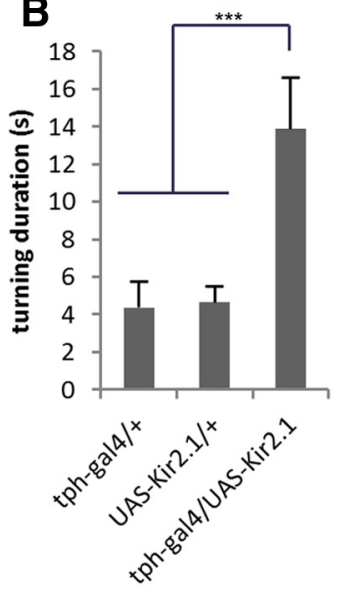

mechanical stimuli

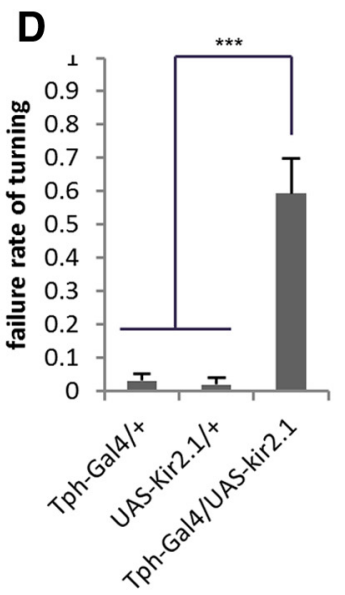

light stimuli

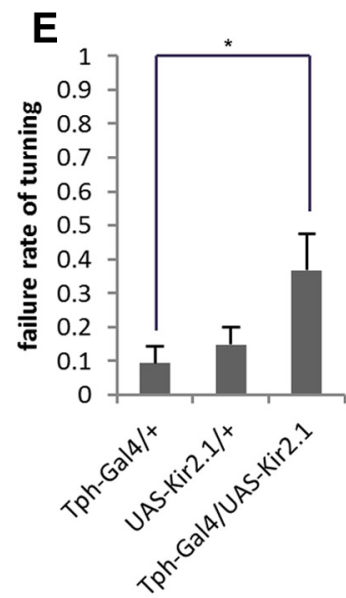

mechanical stimuli
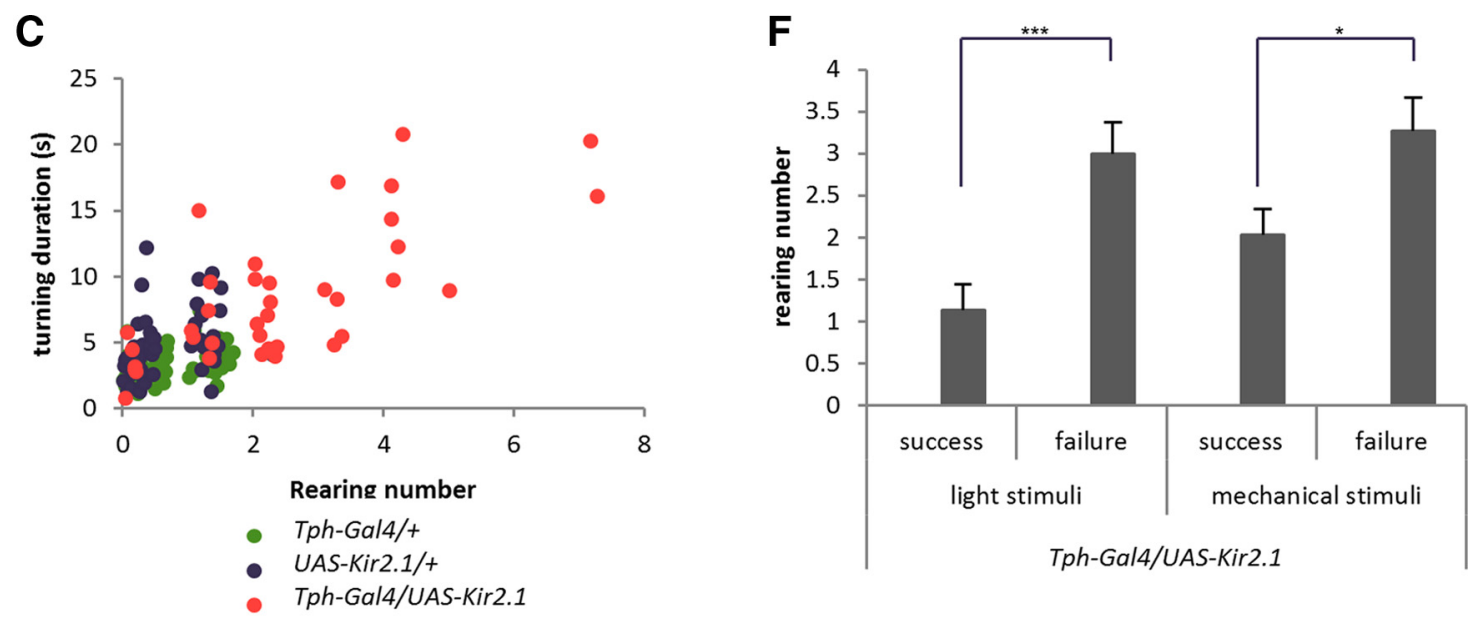

light stimuli

Figure 4. Suppression of rearing by 5 -HT neurons is required for prompt and successful turning. $\boldsymbol{A}-\boldsymbol{F}$, Turning behaviors induced by light $(\boldsymbol{A}, \boldsymbol{C}, \boldsymbol{D}, \boldsymbol{F})$ and mechanical stimuli $(\boldsymbol{B}, \boldsymbol{E}, \boldsymbol{F})$ were analyzed. $\boldsymbol{A}, \boldsymbol{B}$, Duration of turning behavior is increased in Tph-Gal4/UAS-Kir2.1 larvae. The duration was defined as the time between the presentation of the stimuli and restart of peristalsis. $\boldsymbol{C}$, Correlation between the number of rearings and duration of turning behavior during light-induced turning. $\boldsymbol{D}, \boldsymbol{E}$, Failure rate of turning is increased in Tph-Gal4/UAS-Kir2.1 larvae. $\boldsymbol{F}$, Correlation between the number of rearings and success/failure of turning. $n=8-14(\boldsymbol{A}, \boldsymbol{D}) ; n=8-11(\boldsymbol{B}, \boldsymbol{E}) ; n>14(\boldsymbol{C}, \boldsymbol{F})$. All experiments were performed at $32^{\circ} \mathrm{C}$. ${ }^{*} p<0.05{ }^{* * * *} p<0.001[\mathrm{Tukey}-\mathrm{Kramer}$ post hoc test $(\boldsymbol{A}-\boldsymbol{E})$ or Welch's test $(\boldsymbol{F})]$.

$p<0.01, n=10-25$ animals per genotype, one-way ANOVA; Fig. 7C), indicating that transmission by leucokinin neurons is involved in the regulation of rearing during turning. Whereas c127-Gal4 was expressed in ABLKs in the VNC only, it was also expressed in other neurons in the brain and SOG. However, among the c127-Gal4-expressing neurons, only ABLKs expressed 5-HT1B-Gal4 (data not shown). These results suggest that ABLKs are involved in the regulation of rearing. To further test this idea, and the involvement of leucokinin itself, we next expressed shRNA of leucokinin using 5-HT1B-Gal4. Rearing incidence was increased $\left(F_{(2,39)}=8.2, p<0.01, n=8-12\right.$ animals per genotype, one-way ANOVA; Fig. 7D), confirming the involvement of ABLK neurons and leucokinin. Together, our results suggest that during the regulation of rearing, 5-HT signaling is received by ABLK neurons via the 5-HT1B receptor and transmitted to neurons further downstream by secretion of leucokinin (Fig. 8D).

\section{Distribution of leucokinin receptors}

To gain insight into downstream pathway(s) of the 5-HT signaling, we next studied the expression pattern of the leucokinin receptor, which was described previously (Radford et al., 2002; Al-Anzi et al., 2010). Here, we focused our analyses on the expression in the larval VNC. Staining with an antibody showed that the receptor is broadly expressed in the CNS (Fig. $8 A-A^{\prime \prime}$ ). Strong signals were seen in varicosity-like structures in neurites, many of which appeared to align along longitudinal tracts. Notably, expression was seen near the axon terminals of the ABLK neurons at the terminal plexus (Fig. $8 B-B^{\prime \prime}$ ). The terminals of ABLK neurons expressed Syt-GFP and leucokinin, indicating that they may be the presynaptic release sites (data not shown). Expression of the receptor was also seen in the cell bodies of ABLKs, suggesting a possibility of autocrine signaling. In contrast, no signal or only a weak signal was seen in muscles, peripheral neurons, and the body wall (data not shown), suggesting that muscles are not the downstream targets involved in the regulation of rearing.

\section{Activity of leucokinin neurons is regulated by $5-\mathrm{HT}$ and critical for the control of rearing}

We next examined the effect of hyperactivation of ABLK neurons. For this purpose, we expressed the TrpA1 channel in ABLK 
A
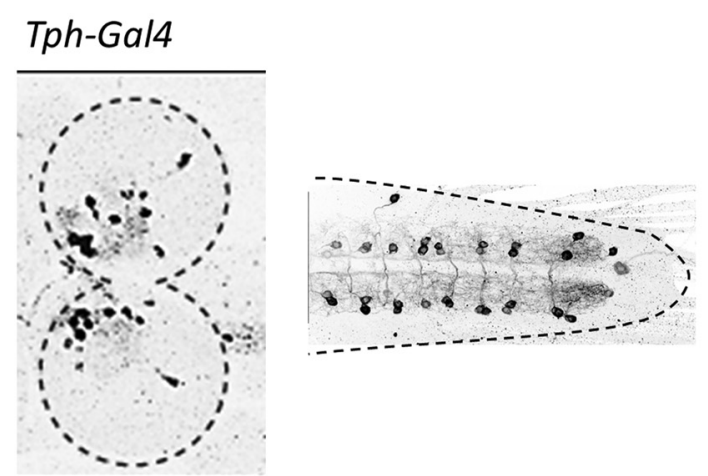

B Tph-Gal4,tsh-Gal80

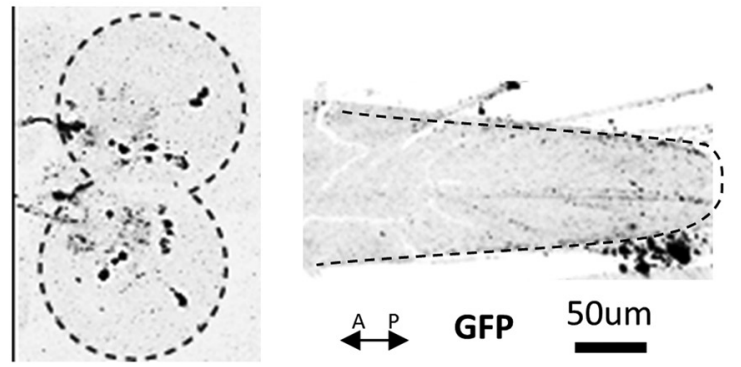

C

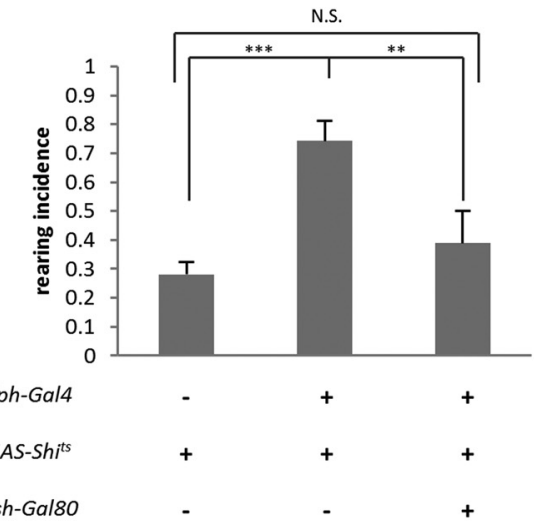

D

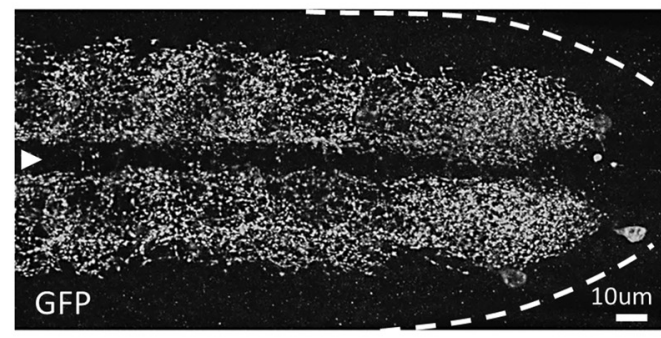

Figure 5. 5-HT neurons in the VNC are involved in the regulation of rearing. A, B, Suppression of Tph-Gal4-driven expression in the VNC, but not in the brain, by tsh-Gal80. Confocal images of mCD8::GFP staining in Tph-Gal4/UAS-mCD8::GFP (A) and Tph-Gal4, tsh-Gal80/UAS-mCD8::GFP (B) larvae are shown. Dashed lines indicate the outline of the brain and the VNC. C, Increase in rearing by expression of Shi ${ }^{\text {ts }}$ is rescued by tsh-Gal80. $n=9-14$. Behavioral assays performed at $32^{\circ} \mathrm{C}$. ${ }^{* *} p<0.01 ;{ }^{* * *} p<0.001$ (Tukey-Kramer post hoc test). $\boldsymbol{D}$, Expression of the synaptotagmin in Tph-Gal4 neurons in the VNC. White dashed lines indicate the outline of the VNC. The white arrowhead indicates the midline.

using the c127-Gal4 line. (The 5-HT1B-Gal4 line could not be used for this purpose because activation of TrpA1 by this Gal4 line caused severe locomotion defects.) We found an increase in rearing by hyperexcitation of $c 127-$ Gal4 neurons $\left(F_{(2,27)}=12.0\right.$, $p<0.001, n=9-19$ animals per genotype, one-way ANOVA; Fig. $9 A$ ). Thus, both activation and inhibition of ABLK neurons led to misregulation of rearing during turning behavior.

To understand how the activity of ABLK neurons is regulated by 5 -HT, we next performed $\mathrm{Ca}^{2+}$ imaging of the activity of ABLKs by expressing GCaMP 3.0 in these neurons. We observed a periodic activation of these neurons with a cycle of $15.00 \pm$ $0.75 \mathrm{~s}$ in the dissected larvae (Fig. 9B, C). In each cycle of activation, ABLK neurons in left and right hemisegments and in different segments are activated simultaneously, suggesting that they receive common or simultaneous inputs. When we added the 5-HT antagonist WAY100635 during the imaging, the activity level (total period in which $\mathrm{Ca}^{2+}$ signal was above a certain threshold) and frequency of the periodic activation decreased (Fig. 9D, F, threshold set to $0.5 \%, F_{(2,29)}=7.7, p<0.01 ; 1 \%$, $F_{(2,29)}=9.2, p<0.001 ; 2 \%, F_{(2,29)}=11.2, p<0.001 ; 3 \%, F_{(2,29)}=$ $12.8, p<0.001 ; 4 \%, F_{(2,29)}=9.7, p<0.001 ; 6 \%, F_{(2,29)}=9.1, p<$ $0.001 ; 8 \%, F_{(2,29)}=10.3, p<0.001 ; 10-12$ ROIs in five to six animals per group, one-way ANOVA; Fig. $9 F, p<0.05$ when the threshold is set to $1-4 \%$, Tukey-Kramer post hoc test; Fig. $9 G$, $F_{(2,29)}=12.3, p<0.001,10-12$ ROIs in five to six animals per group, one-way ANOVA; $p<0.05$, Tukey-Kramer post hoc test). Conversely, application of the 5-HT agonist 8-OH-DPAT increased the activity level of ABLK neurons (Fig. 9E, F; $p<0.05$ when the threshold is set to $8 \%$, Tukey-Kramer post hoc test). Thus, 5-HT acts in an excitatory manner to increase the level of ABLK activity. These results suggest that ABLK neurons are acti- vated periodically in a resting state, and the activity can be modulated by 5 -HT.

\section{Discussion}

Regulation of turning behavior by $5-\mathrm{HT}$

In this work, we first quantitatively analyzed the behavioral components included in larval turning. Whereas previous studies of Drosophila turning behavior largely focused on the most common component, bending (Yang et al., 2000; Caldwell et al., 2003; Suster et al., 2003, 2004; Ainsley et al., 2008; Luo et al., 2010; Lahiri et al., 2011; Berni et al., 2012), we measured all three behavioral components involved in the directional change. We initially evoked reorientation using a blue light stimulus and found that the directional change consisted of three behavioral components-bending, retreating, and rearing-the combination of which was variable across events. The same was true when a mechanical stimulus was used to trigger the turning behavior. Thus, the larvae appear to choose the combination of the behavioral components by integrating environmental information when they receive the noxious stimuli. Both in light-triggered and mechanically triggered turning, bending was the most frequent component and happened at least once, whereas retreating and rearing occurred at a lower frequency. These observations suggest that whereas bending is an essential behavioral component of turning, retreating and rearing may play only subsidiary roles.

We found that when transmission of 5-HT neurons was inhibited, occurrence of rearing was greatly increased. Conversely, administration of a 5-HT receptor agonist decreased rearing incidence. Thus, 5-HT suppresses rearing during turning. In both experiments, the occurrence of bending and retreating was not affected. Thus, 5-HT does not act as a switch between rearing and 

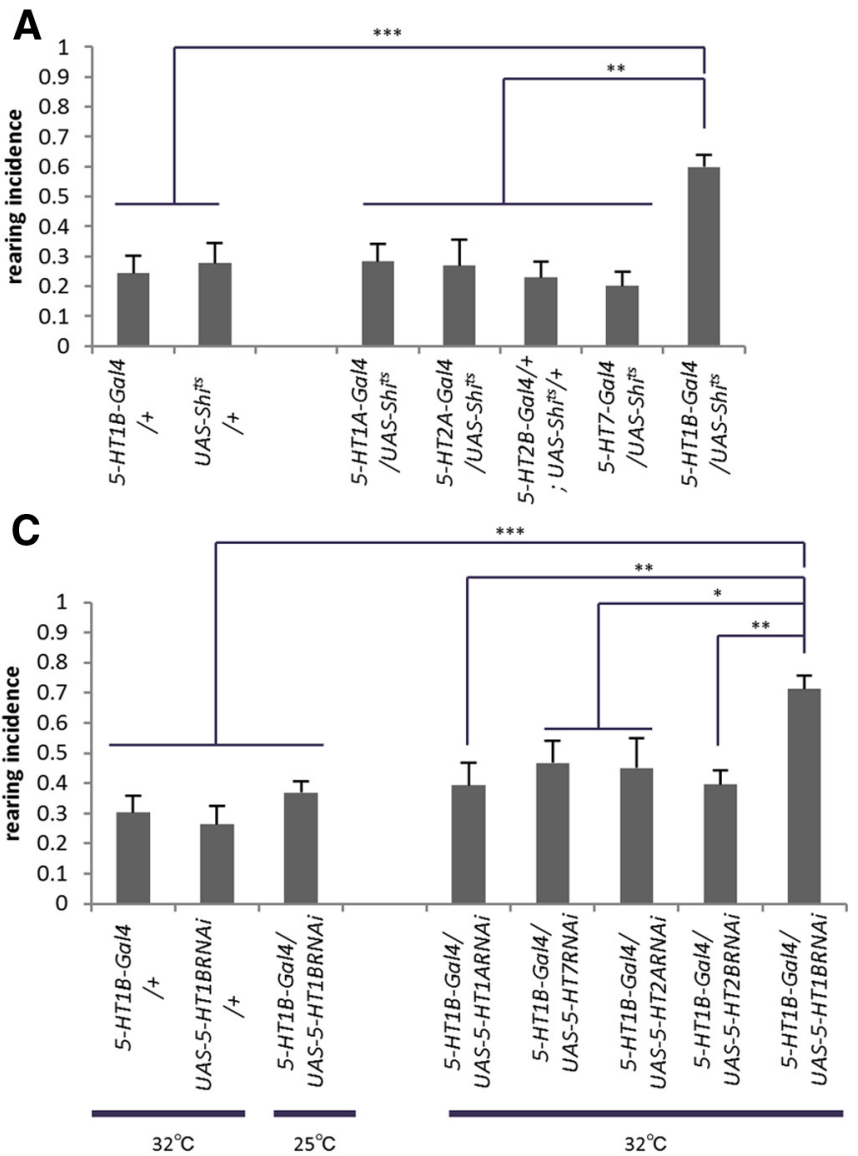

B

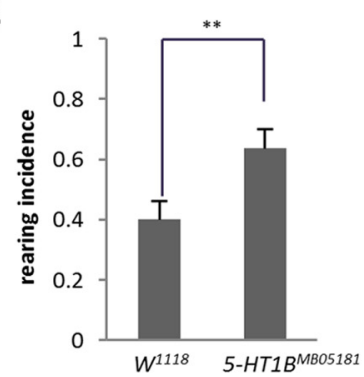

\section{I}
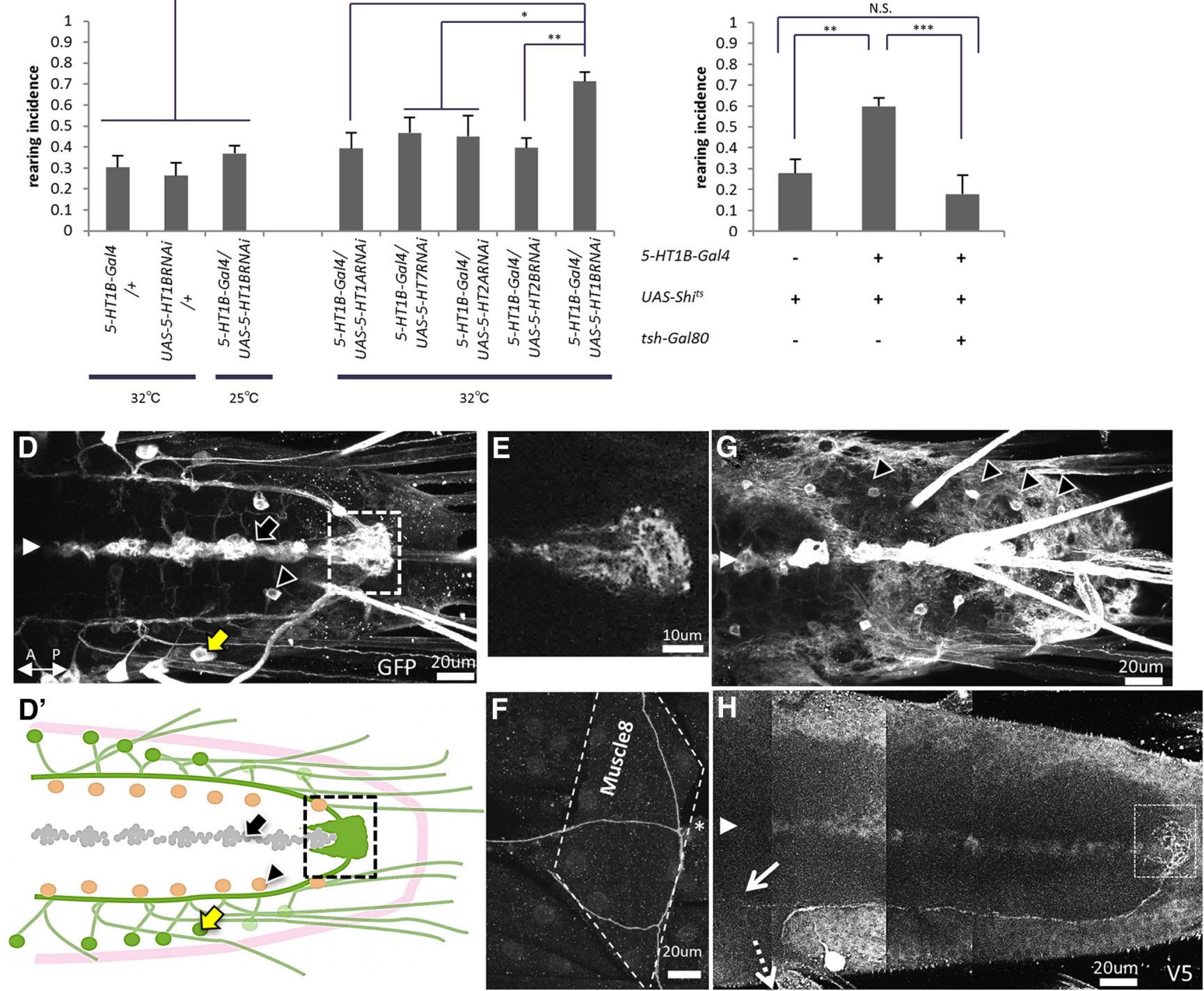

Figure 6. The 5-HT1B receptor is involved in the regulation of rearing. A, Rearing was increased when Shit ${ }^{\text {s }}$ was expressed by 5-HT1B-Gal4, but not by 5-HT1A-Gal4, 5-HT2A-Gal4, 5-HT2B-Gal4, or 5-HT7-Gal4 ( $n=7-14)$. $B$, Increased rearing in 5-HT1B mutants $(n=10-11)$. C, Rearing was increased when shRNA of 5-HT1B, but not 5-HT1A, 5-HT2A, 5-HT2B, or 5-HT7 receptors, were expressed by 5-HT1B-Gal4 ( $n=9-16)$. An increase in rearing was not observed in 5-HT1B-Gal4/UAS-5-HT1BRNAi larvae when the behavioral assay was performed at $25^{\circ} \mathrm{C}$. $D, G, C$ onfocal images showing the expression of 5-HT1B-Gal4 in the VNC at different focal planes (visualized with mCD8::GFP). $\boldsymbol{D}^{\prime}$, A schema of $\boldsymbol{D}$ and $\mathbf{G}$ showing the morphology of three populations of 5-HT1B-Gal4 neurons; ABLK neurons (green, yellow arrow in $\boldsymbol{D}$ ), which project axons toward the terminal plexus (dashed square); and cells in the midline (gray, black arrow in $\boldsymbol{D}$ ); and an identified interneuron in each hemisegment (orange, black triangles in $\boldsymbol{D}, \boldsymbol{G}$ ). The region outlined by dashed lines is enlarged in $\boldsymbol{E}$. The white arrowhead indicates the midline in $\boldsymbol{D}, \boldsymbol{G}$, and $\boldsymbol{H} . \boldsymbol{E}, \boldsymbol{F}, \mathrm{Axon}$ terminals of $A B L K$ neurons, one at the terminal plexus at the posterior end of the $\operatorname{VNC}(\boldsymbol{E})$ and the other on muscle $8(\boldsymbol{F})$. $\boldsymbol{H}$, A confocal image of a single ABLK neuron visualized by the Flybow technique. Neurites of an ABLK neuron project to the terminal plexus (white dashed square), toward anterior segments (white arrow), and to the periphery (white dashed arrow). $I$, Increase of rearing by expression of Shi ${ }^{\text {ts }}$ in 5-HT1B-Gal4 neurons was rescued by tsh-Gal80. $n=9-10$. All behavioral assays $(\boldsymbol{A}-\boldsymbol{C}, \boldsymbol{I})$ were performed at $32^{\circ} \mathrm{C}$ unless noted otherwise. ${ }^{*} p<0.05$; ${ }^{* *} p<0.01{ }^{* * * *} p<0.001[$ Tukey-Kramer post hoc test $(\boldsymbol{A}, \boldsymbol{C}, \boldsymbol{H})$ or Welch's test $(\boldsymbol{B})]$. 


\section{5-HT1B-Gal4/UAS-mCD8::GFP}

A

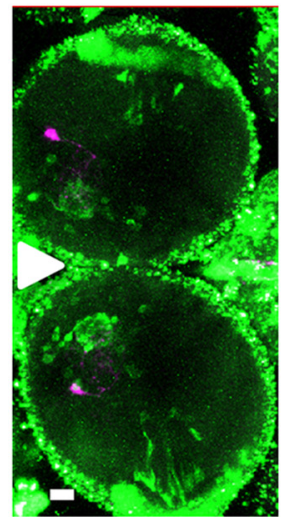

A'

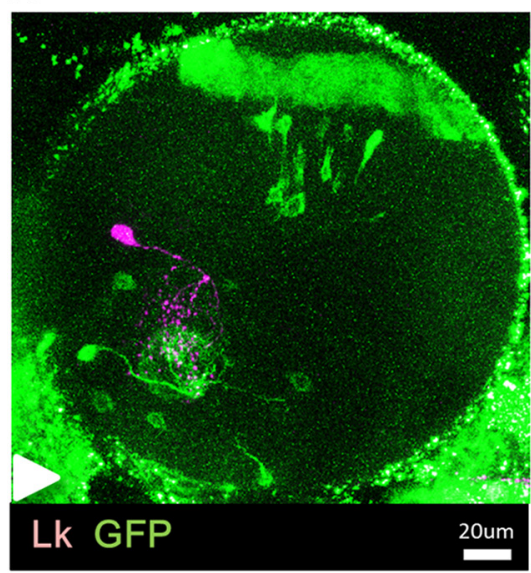

B

B'
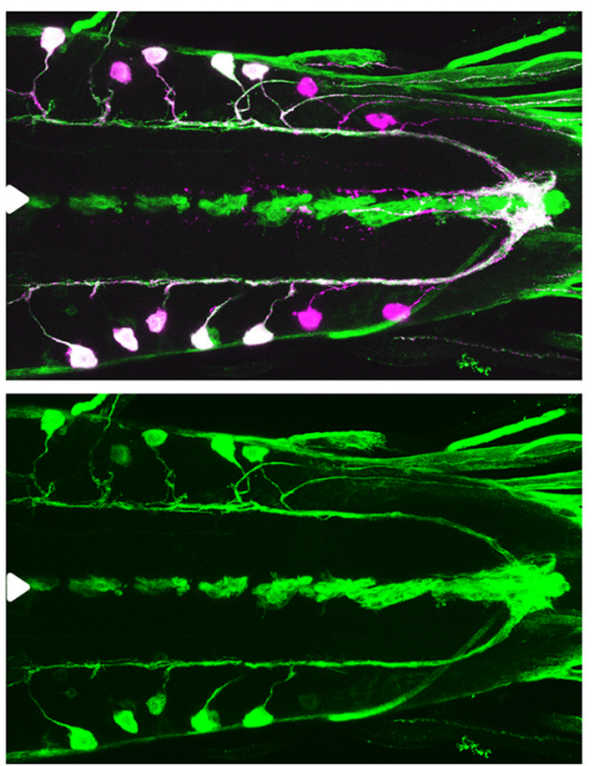

B"

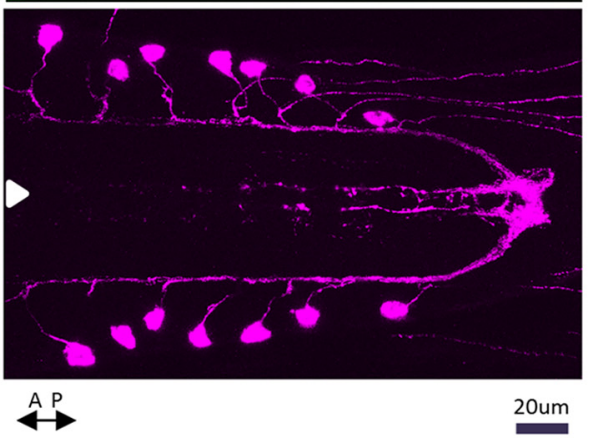

C
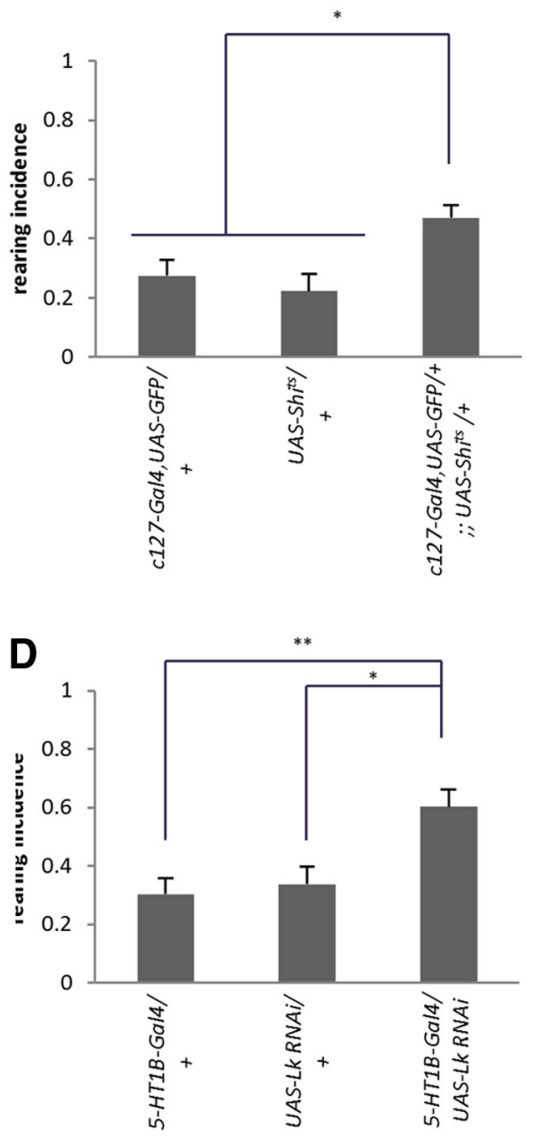

Figure 7. Leucokinin transmission by 5-HT1B-positive ABLK neurons is involved in the regulation of rearing. $\boldsymbol{A}-\boldsymbol{B}^{\prime \prime}$, Double staining for mCD8::GFP expressed by 5-HT1B-Gal4 (green) and leucokinin (purple). $\boldsymbol{A}$, Frontal view of the brain. $\boldsymbol{A}^{\prime}$, Enlarged view of $\boldsymbol{A} . \boldsymbol{B}, \boldsymbol{B}^{\prime}$, Expression in the VNC. 5-HT1B-Gal4 expression in $A 1$ and $A 2$ is weaker compared with that in other neuromeres. Signals for 5-HT1B-Gal4 and leucokinin overlap in the ABLK neurons $\left(\boldsymbol{B}-\boldsymbol{B}^{\prime \prime}\right)$, but not in the brain $\left(\boldsymbol{A}, \boldsymbol{A}^{\prime}\right)$. The white arrowheads indicate the midline. $\boldsymbol{C}$, Inhibition of leucokinin neurons in $\mathbf{C}$ 27-Gal4,UASGFP/+; UAS-Shits $/+$ larvae increased rearing $(n=10-25)$. $\boldsymbol{D}$, shRNA-mediated knockdown of leucokinin in 5-HT1B-Gal4 neurons increased rearing $(n=8-12)$. Behavioral assays in $C$ and $\boldsymbol{D}$ were performed at $32^{\circ} \mathrm{C} .{ }^{*} p<0.05 ;{ }^{* *} p<0.01$ (Tukey-Kramer post hoc test).

bending or retreating. Instead, our results indicate that serotonergic circuits specifically modulate rearing among the alternative behaviors during turning. It should be noted that the effect of 5-HT manipulation was temperature dependent. During both light-induced and mechanically induced turning, 5-HT inhibition increased rearing at $32^{\circ} \mathrm{C}$, but not at $25^{\circ} \mathrm{C}$. The effect of a 5-HT agonist was also temperature dependent. This was also the case for an increase in rearing when the 5-HT1B receptor was knocked down by shRNA. Thus, 5-HT signaling appears to control rearing only when a noxious heat stimulus is presented in addition to the light and mechanical stimuli. The role of 5-HT in rearing control is independent of the role of 5-HT in developmental changes in light reactivity reported previously (Rodriguez Moncalvo and Campos, 2009). An increase in rearing upon 5-HT inhibition was observed at both the foraging and wandering stages (Fig. 2G). Furthermore, whereas 5-HT neurons in the brain are involved in the change of light reactivity (Rodriguez Moncalvo and Campos, 2009), 5-HT neurons in the VNC are involved in the control of rearing (Fig. 5C).

When rearing was excessively increased with 5-HT inhibition, the turning or directional change took longer and sometimes failed to occur. Thus, 5-HT-mediated suppression of rearing is critical for efficient turning. What, then, is the purpose of rearing during normal turning behavior? Bending and retreating are obviously suited for escape behavior because they move the larvae away from the noxious stimulus. In contrast, during rearing, the larvae stay near the site of the noxious stimuli, although their anterior part is lifted away from the stimulus. One possibility is that rearing is an escape behavior that allows the larvae to escape from noxious stimuli and crawl on a new substrate in threedimensional space. Another possibility is that rearing is a search behavior that allows the larvae to sense the vertical environment (Benz, 1956; Green et al., 1983).

\section{Leucokinin transmission as the downstream target of 5-HT}

5-HT signaling can be transmitted locally through secretion at the synapse or globally by secretion in the body fluid. We used tsh-Gal80 to show that suppression of 5-HT inhibition in the VNC was sufficient to rescue the rearing phenotype in TphGal4/+; UAS-Shits/+ larvae. This suggests that local 5-HT signaling within the $\mathrm{VNC}$ is involved in the control of rearing. Then we showed that neurons expressing the 5 -HT1B receptor are the downstream targets of $5-\mathrm{HT}$. Inhibition of these neurons in the 5-HT1B mutants by 5-HT1B RNAi knockdown and expression of $\mathrm{Shi}^{\text {ts }}$, but not manipulation of neurons expressing other 5-HT receptors, recapitulated the rearing phenotype observed when 
c127-Gal4, UAS-mCD8::GFP
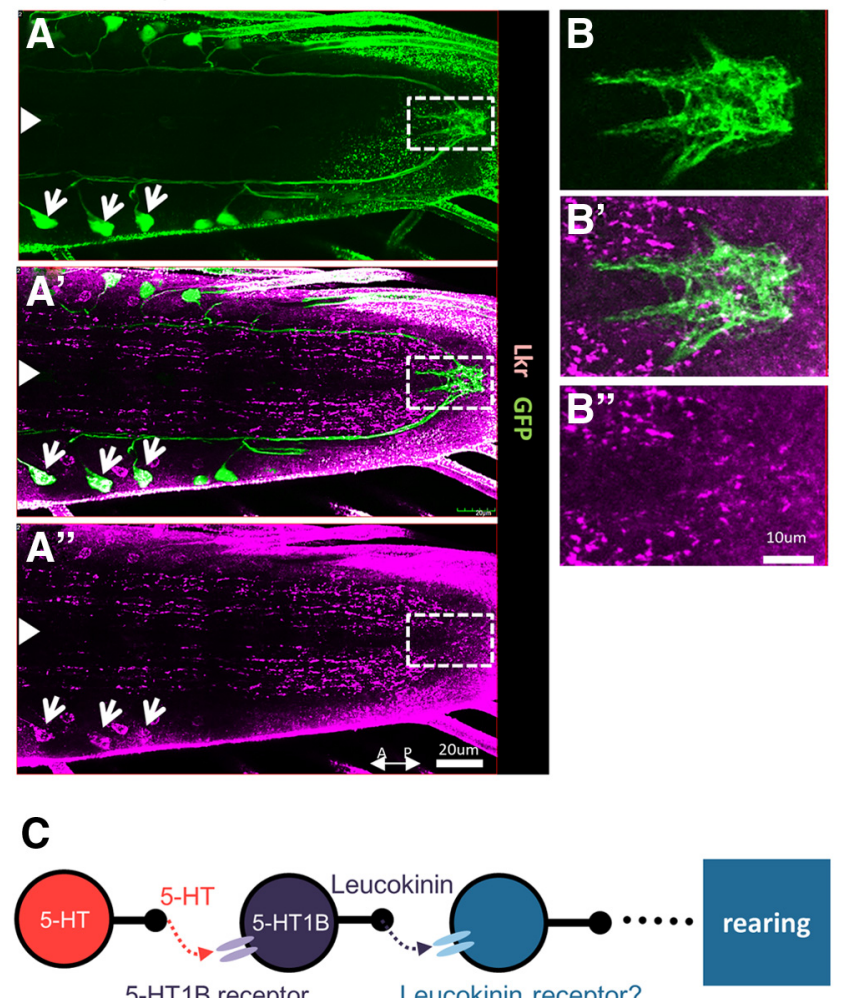

Figure 8. Visualization of leucokinin receptors in the VNC. $\boldsymbol{A}-\boldsymbol{B}^{\prime \prime}$, Confocal images of larval VNCs stained for the leucokinin receptor (purple) and mCD8::GFP (expressed by c127-Gal4; green). Expression in ABLK cell bodies is indicated by white arrows. The region demarcated by white dotted rectangles in $\boldsymbol{A}-\boldsymbol{A}^{\prime \prime}$ is enlarged in $\boldsymbol{B}-\boldsymbol{B}^{\prime \prime}$ to show expression in the plexus near the axon terminals of ABLKs. White arrowheads indicate the midline. $\boldsymbol{C}$, A model showing the signaling pathway of $5-\mathrm{HT}$ involved in the regulation of rearing.

5-HT transmission was blocked. The local nature of the 5-HT signaling was also supported by the rescue of the 5-HT1B RNAi knockdown phenotype by tsh-Gal80. Furthermore, we identified leucokinin-expressing ABLKs as being involved in the rearing regulation, among the 5-HT1B-expressing cells. Expression of $\mathrm{Shi}^{\text {ts }}$ in these neurons recapitulated the rearing phenotype. RNAi knockdown of leucokinin in 5-HT1B-Gal4-expressing neurons also recapitulated the rearing phenotype. Since ABLKs are the only leucokinin-expressing neurons that express 5-HT1B-Gal4, the results indicate that ABLKs are involved in rearing control. Our results also show that leucokinin transmission by ABLKs is involved in rearing control, and that a highly specific neural pathway downstream of 5-HT, including 5-HT1B receptors and leucokinin transmission, is involved in the control of rearing (Fig. 8C).

Leucokinin is known as an insect hormone that regulates fluid secretion in some insects (O'Donnell et al., 1998; Terhzaz et al., 1999; Nässel, 2002). In Drosophila, leucokinin controls food intake, chemosensory responses, and fluid homeostasis in adults (Al-Anzi et al., 2010; Cognigni et al., 2011; López-Arias et al., 2011). Only a single neuron type, ABLK, expresses leucokinin in each segment of the larval VNC and has a unique morphology. This neuron extends axonal projections both within the CNS and to the periphery. The axon projection to the periphery terminates on lateral muscle 8 . The terminal of ABLK is distinct from those of motor neurons since it contains no bouton-like structures and is classified as a type-3u terminal (Cantera and Nässel, 1992; Landgraf et al., 2003). However, our anatomical analyses of the leucokinin receptor suggest that muscles are not direct targets of ABLKs in the regulation of rearing. The other axon of ABLK terminates in the terminal plexus within the VNC. The terminal expresses Syt-GFP and leucokinin, suggesting that leucokinin is secreted from the terminal. We observed leucokinin receptor expression in the vicinity of the ABLK terminal, suggesting the possibility that leucokinin signaling is synaptically transmitted to the downstream neurons at this site. However, since leucokinin can be secreted and function extrasynaptically, the signal may be transmitted through leucokinin receptors that we observed in other regions of the VNC. Interestingly, we observed expression of the leucokinin receptor in ABLK neurons. This suggests the possibility that ABLKs regulate their own activity through autocrine signaling. Since 5-HT signaling appears to specifically control rearing among the behaviors of the larvae including peristaltic locomotion, bending, and rolling, the downstream neurons likely involve neurons responsible for the regulation of rearing. Rearing requires coordinated activation of a defined set of muscles in the anterior segments. It would be interesting to study in the future whether downstream targets of 5-HT signaling include interneurons involved in this coordination.

\section{Activity level of ABLK neurons is regulated by 5-HT}

We observed that not only inhibition but also forced activation of leucokinin neurons increased rearing incidence. The data suggest that an appropriate level of ABLK activity is critical for rearing control. Calcium imaging demonstrated that ABLKs have cyclic activity with an interval of $\sim 15 \mathrm{~s}$. The frequency of the cyclic activity was increased by a 5-HT agonist and decreased by a 5-HT antagonist. The effects of the 5-HT agonist and antagonist suggest that 5-HT increases the activity level of ABLKs. The 5-HT1B receptor is a G-protein-coupled receptor orthologous to human 5-HT1A (Blenau and Thamm, 2011), which is known to have inhibitory effects on neural activity (Millan et al., 2008). Drosophila 5-HT1B has been shown to inhibit adenylate cyclase and activate phospholipase C (Saudou et al., 1992). It is therefore possible that activity of ABLKs is regulated through cAMP and/or $\mathrm{IP}_{3}$ signaling.

The effects of the 5-HT agonist on rearing in the larvae fed with this drug and on ABLK activity in calcium imaging are somewhat contradictory. Calcium imaging experiments showed that the agonist increases the activity level of ABLKs. Since the experiments with TrpA1 showed that increased activity of ABLKs results in increased rearing, the agonist should increase rearing. However, the administration of the agonist in the larvae instead decreased rearing. This could be due to the temporal difference in the administration of the agonist in the two experiments (chronic administration in the behavioral experiments vs acute administration in the calcium imaging). The discrepancy also could be due to the quantitative and qualitative differences in the activation by the agonist and by TrpA1. In any case, these results suggest that 5-HT modulates larval turning by regulating the level of ABLK activity.

In conclusion, we found that 5-HT modulates larval turning by specifically suppressing one of its three behavioral components, rearing. We also demonstrated the involvement of downstream ABLK neurons and leucokinin. Our results suggest that 5 -HT regulates turning by changing the periodic activity level of ABLK neurons and secretion of the neuropeptide. These results reveal a novel mechanism by which 5-HT exerts its effect on the modulation of behavior. 
A

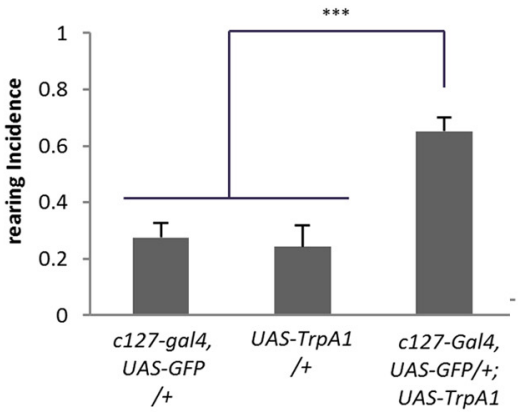

C

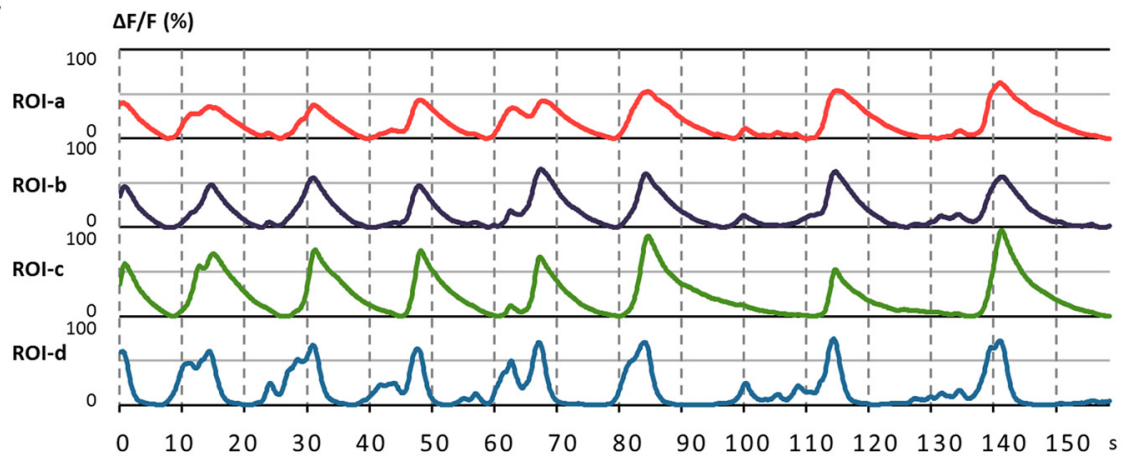

D

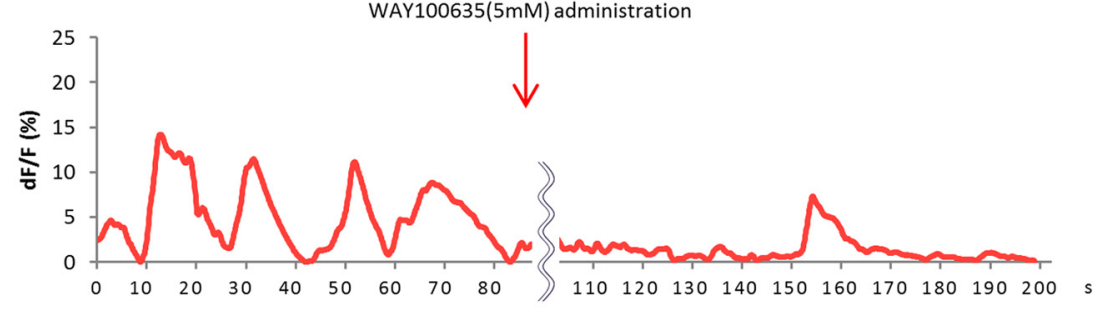

E

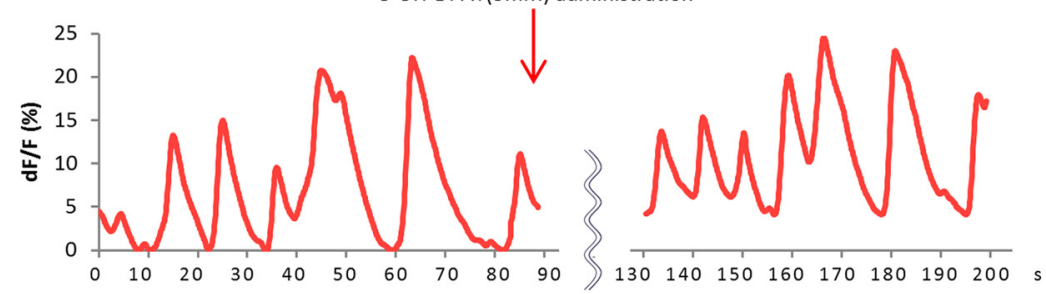

$\mathbf{F}$

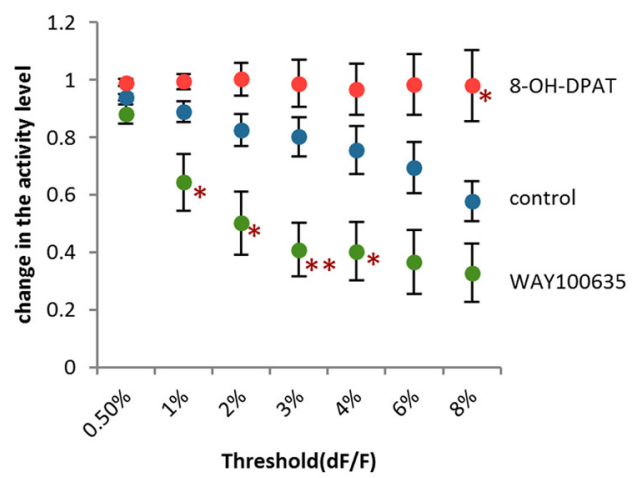

B

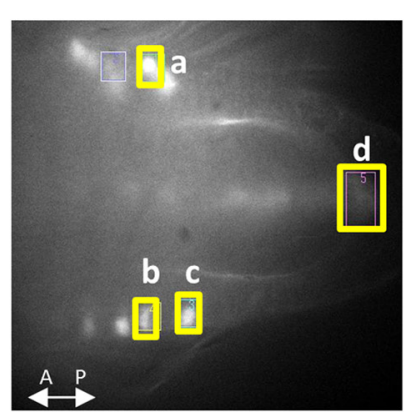

G

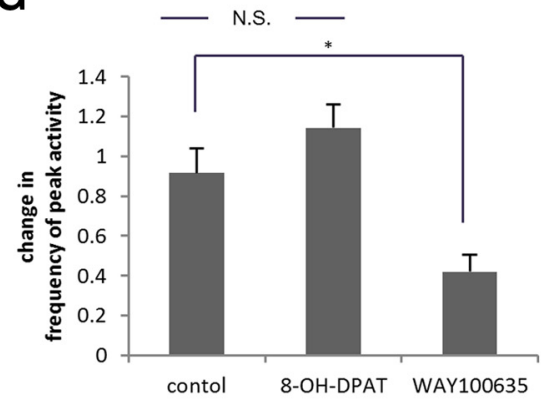

Figure 9. The activity level of leucokinin neurons is critical for the control of rearing and is regulated by 5-HT. A, Activation of leucokinin neurons in C127-Gal4,UAS-GFP/+; UAS-TrpA1/+ larvae increased rearing $(n=9-19)$. B, C, Calcium imaging of ABLK neurons in a dissected 5-HT1B-Gal4/UAS-GCaMP3 larva. The fluorescence intensities (\% $\triangle F / F)$ of four ROIs indicated by yellow boxes were plotted. Comparison of the timing of the increase in fluorescence between ABLK cells in left and right hemisegments (ROI-a vs ROI-b) and between cells in the neighboring segments (ROI-b vs ROI-c) show that they are activated simultaneously. The activity rise in the putative axon terminals of ABLKs (ROI-d) shows slightly different kinetics than that in the cell bodies (ROI-a-ROI-c), but is largely simultaneous to the activation of the cells. $\mathbf{D}-\mathbf{G}$, The effects of the 5 -HT antagonist $(\boldsymbol{D} ;$ WAY100635) and agonist (E; 8-OH-DPAT). Red arrows indicate the time the drugs were applied. The average fluorescence intensity of the ROl in the ABLK cell body is plotted. The change in the activity level $(\boldsymbol{F})$ and frequency of peak activity $(\Delta F / F>4 \% ; \boldsymbol{G})$ were statistically analyzed as described in Materials and Methods. ${ }^{*} p<0.05 ;{ }^{* *} p<0.01 ;{ }^{* *} p<0.001$, compared with control (Tukey-Kramer post hoc test; $10-12$ ROls in $5-6$ larvae were analyzed). 


\section{References}

Ainsley JA, Kim MJ, Wegman LJ, Pettus JM, Johnson WA (2008) Sensory mechanisms controlling the timing of larval developmental and behavioral transitions require the Drosophila DEG/ENaC subunit, Pickpocket1. Dev Biol 322:46-55. CrossRef Medline

Al-Anzi B, Armand E, Nagamei P, Olszewski M, Sapin V, Waters C, Zinn K, Wyman RJ, Benzer S (2010) The leucokinin pathway and its neurons regulate meal size in Drosophila. Curr Biol 20:969-978. CrossRef Medline

Baines RA, Uhler JP, Thompson A, Sweeney ST, Bate M (2001) Altered electrical properties in Drosophila neurons developing without synaptic transmission. J Neurosci 21:1523-1531. Medline

Bargmann CI (2012) Beyond the connectome: how neuromodulators shape neural circuits. Bioessays 34:458-465. CrossRef Medline

Benz G (1956) Der trockenheitssinn bei larven von Drosophila melanogaster. Experientia 12:297-298. CrossRef

Berni J, Pulver SR, Griffith LC, Bate M (2012) Autonomous circuitry for substrate exploration in freely moving Drosophila larvae. Curr Biol 22: 1861-1870. CrossRef Medline

Blenau W, Thamm M (2011) Distribution of serotonin (5-HT) and its receptors in the insect brain with focus on the mushroom bodies: lessons from Drosophila melanogaster and Apis mellifera. Arthropod Struct Dev 40:381-394. CrossRef Medline

Brand AH, Perrimon N (1993) Targeted gene expression as a means of altering cell fates and generating dominant phenotypes. Development 118: 401-415. Medline

Caldwell JC, Miller MM, Wing S, Soll DR, Eberl DF (2003) Dynamic analysis of larval locomotion in Drosophila chordotonal organ mutants. Proc Natl Acad Sci U S A 100:16053-16058. CrossRef Medline

Cantera R, Nässel DR (1992) Segmental peptidergic innervation of abdominal targets in larval and adult dipteran insects revealed with an antiserum against leucokinin I. Cell Tissue Res 269:459-471. CrossRef Medline

Chen J, Condron BG (2008) Branch architecture of the fly larval abdominal serotonergic neurons. Dev Biol 320:30-38. CrossRef Medline

Clyne JD, Miesenböck G (2008) Sex-specific control and tuning of the pattern generator for courtship song in Drosophila. Cell 133:354-363. CrossRef Medline

Cognigni P, Bailey AP, Miguel-Aliaga I (2011) Enteric neurons and systemic signals couple nutritional and reproductive status with intestinal homeostasis. Cell Metab 13:92-104. CrossRef Medline

Cole SH, Carney GE, McClung CA, Willard SS, Taylor BJ, Hirsh J (2005) Two functional but noncomplementing Drosophila tyrosine decarboxylase genes: distinct roles for neural tyramine and octopamine in female fertility. J Biol Chem 280:14948-14955. CrossRef Medline

de Haro M, Al-Ramahi I, Benito-Sipos J, López-Arias B, Dorado B, Veenstra JA, Herrero P (2010) Detailed analysis of leucokinin-expressing neurons and their candidate functions in the Drosophila nervous system. Cell Tissue Res 339:321-336. CrossRef Medline

Friggi-Grelin F, Coulom H, Meller M, Gomez D, Hirsh J, Birman S (2003) Targeted gene expression in Drosophila dopaminergic cells using regulatory sequences from tyrosine hydroxylase. J Neurobiol 54:618-627. CrossRef Medline

Gasque G, Conway S, Huang J, Rao Y, Vosshall LB (2013) Small molecule drug screening in Drosophila identifies the 5HT2A receptor as a feeding modulation target. Sci Rep 3:srep02120. Medline

Getting PA (1989) Emerging principles governing the operation of neural networks. Annu Rev Neurosci 12:185-204. CrossRef Medline

Gomez-Marin A, Louis M (2012) Active sensation during orientation behavior in the Drosophila larva: more sense than luck. Curr Opin Neurobiol 22:208-215. CrossRef Medline

Green CH, Burnet B, Connolly KJ (1983) Organization and patterns of inter- and intraspecific variation in the behaviour of Drosophila larvae. Anim Behav 31:282-291. CrossRef

Hadjieconomou D, Rotkopf S, Alexandre C, Bell DM, Dickson BJ, Salecker I (2011) Flybow: genetic multicolor cell labeling for neural circuit analysis in Drosophila melanogaster. Nat Methods 8:260-266. CrossRef Medline

Hamada FN, Rosenzweig M, Kang K, Pulver SR, Ghezzi A, Jegla TJ, Garrity PA (2008) An internal thermal sensor controlling temperature preference in Drosophila. Nature 454:217-220. CrossRef Medline

Harris-Warrick RM, Cohen AH (1985) Serotonin modulates the central pattern generator for locomotion in the isolated lamprey spinal cord. J Exp Biol 116:27-46. Medline
Harris-Warrick RM, Marder E (1991) Modulation of neural networks for behavior. Annu Rev Neurosci 14:39-57. CrossRef Medline

Hewes RS, Park D, Gauthier SA, Schaefer AM, Taghert PH (2003) The bHLH protein Dimmed controls neuroendocrine cell differentiation in Drosophila. Development 130:1771-1781. CrossRef Medline

Huser A, Rohwedder A, Apostolopoulou AA, Widmann A, Pfitzenmaier JE, Maiolo EM, Selcho M, Pauls D, von Essen A, Gupta T, Sprecher SG, Birman S, Riemensperger T, Stocker RF, Thum AS (2012) The serotonergic central nervous system of the Drosophila larva: anatomy and behavioral function. PLoS One 7:e47518. CrossRef Medline

Johnson O, Becnel J, Nichols CD (2009) Serotonin 5-HT 2 and 5-HT 1Alike receptors differentially modulate aggressive behaviors in Drosophila melanogaster. Neuroscience 158:1292-1300. CrossRef Medline

Johnson O, Becnel J, Nichols CD (2011) Serotonin receptor activity is necessary for olfactory learning and memory in Drosophila melanogaster. Neuroscience 192:372-381. CrossRef Medline

Kane EA, Gershow M, Afonso B, Larderet I, Klein M, Carter AR, de Bivort BL, Sprecher SG, Samuel AD (2013) Sensorimotor structure of Drosophila larva phototaxis. Proc Natl Acad Sci U S A 110:E3868-E3877. CrossRef Medline

Kitamoto T (2001) Conditional modification of behavior in Drosophila by targeted expression of a temperature-sensitive shibire allele in defined neurons. J Neurobiol 47:81-92. CrossRef Medline

Lahiri S, Shen K, Klein M, Tang A, Kane E, Gershow M, Garrity P, Samuel AD (2011) Two alternating motor programs drive navigation in Drosophila larva. PLoS One 6:e23180. CrossRef Medline

Landgraf M, Sánchez-Soriano N, Technau GM, Urban J, Prokop A (2003) Charting the Drosophila neuropile: a strategy for the standardised characterisation of genetically amenable neurites. Dev Biol 260:207-225. CrossRef Medline

Lee T, Luo L (1999) Mosaic analysis with a repressible cell marker for studies of gene function in neuronal morphogenesis. Neuron 22:451-461. CrossRef Medline

López-Arias B, Dorado B, Herrero P (2011) Blockade of the release of the neuropeptide leucokinin to determine its possible functions in fly behavior: chemoreception assays. Peptides 32:545-552. CrossRef Medline

Luo J, Becnel J, Nichols CD, Nässel DR (2012) Insulin-producing cells in the brain of adult Drosophila are regulated by the serotonin 5-HT1A receptor. Cell Mol life Sci 69:471-484. CrossRef Medline

Luo L, Gershow M, Rosenzweig M, Kang K, Fang-Yen C, Garrity PA, Samuel AD (2010) Navigational decision making in Drosophila thermotaxis. J Neurosci 30:4261-4272. CrossRef Medline

Millan MJ, Marin P, Bockaert J, Mannoury la Cour C (2008) Signaling at G-protein-coupled serotonin receptors: recent advances and future research directions. Trends Pharmacol Sci 29:454-464. CrossRef Medline

Nässel DR (2002) Neuropeptides in the nervous system of Drosophila and other insects: multiple roles as neuromodulators and neurohormones. Prog Neurobiol 68:1-84. CrossRef Medline

Nichols CD (2007) 5-HT2 receptors in Drosophila are expressed in the brain and modulate aspects of circadian behaviors. Dev Neurobiol 67:752-763. CrossRef Medline

Nose A, Umeda T, Takeichi M (1997) Neuromuscular target recognition by a homophilic interaction of connectin cell adhesion molecules in Drosophila. Development 124:1433-1441. Medline

O'Donnell MJ, Rheault MR, Davies SA, Rosay P, Harvey BJ, Maddrell SH, Kaiser K, Dow JA (1998) Hormonally controlled chloride movement across Drosophila tubules is via ion channels in stellate cells. Am J Physiol 274:R1039-R1049. Medline

Ohyama T, Jovanic T, Denisov G, Dang TC, Hoffmann D, Kerr RA, Zlatic M (2013) High-throughput analysis of stimulus-evoked behaviors in Drosophila larva reveals multiple modality-specific escape strategies. PLoS One 8:e71706. CrossRef Medline

Orlovsky GN, Dliagina TG, Grillner S (1999) Neural control of locomotion. Oxford, UK: Oxford UP.

Park J, Lee SB, Lee S, Kim Y, Song S, Kim S, Bae E, Kim J, Shong M, Kim JM, Chung J (2006) Mitochondrial dysfunction in Drosophila PINK1 mutants is complemented by parkin. Nature 441:1157-1161. CrossRef Medline

Popescu IR, Frost WN (2002) Highly dissimilar behaviors mediated by a multifunctional network in the marine mollusk Tritonia diomedea. J Neurosci 22:1985-1993. Medline

Radford JC, Davies SA, Dow JA (2002) Systematic G-protein-coupled re- 
ceptor analysis in Drosophila melanogaster identifies a leucokinin receptor with novel roles. J Biol Chem 277:38810-38817. CrossRef Medline

Rodriguez Moncalvo VG, Campos AR (2009) Role of serotonergic neurons in the Drosophila larval response to light. BMC Neurosci 10:66. CrossRef Medline

Santos JG, Vömel M, Struck R, Homberg U, Nässel DR, Wegener C (2007) Neuroarchitecture of peptidergic systems in the larval ventral ganglion of Drosophila melanogaster. PLoS One 2:e695. CrossRef Medline

Saudou F, Boschert U, Amlaiky N, Plassat JL, Hen R (1992) A family of Drosophila serotonin receptors with distinct intracellular signalling properties and expression patterns. EMBO J 11:7-17. Medline

Sitaraman D, Zars M, Laferriere H, Chen YC, Sable-Smith A, Kitamoto T, Rottinghaus GE, Zars T (2008) Serotonin is necessary for place memory in Drosophila. Proc Natl Acad Sci U S A 105:5579-5584. CrossRef Medline

Suster ML, Martin JR, Sung C, Robinow S (2003) Targeted expression of tetanus toxin reveals sets of neurons involved in larval locomotion in Drosophila. J Neurobiol 55:233-246. CrossRef Medline

Suster ML, Karunanithi S, Atwood HL, Sokolowski MB (2004) Turning behavior in Drosophila larvae: a role for the small scribbler transcript. Genes Brain Behav 3:273-286. CrossRef Medline

Sykes PA, Condron BG (2005) Development and sensitivity to serotonin of Drosophila serotonergic varicosities in the central nervous system. Dev Biol 286:207-216. CrossRef Medline

Terhzaz S, O'Connell FC, Pollock VP, Kean L, Davies SA, Veenstra JA, Dow JA (1999) Isolation and characterization of a leucokinin-like peptide of Drosophila melanogaster. J Exp Biol 202:3667-3676. Medline

Tian L, Hires SA, Mao T, Huber D, Chiappe ME, Chalasani SH, Petreanu L, Akerboom J, McKinney SA, Schreiter ER, Bargmann CI, Jayaraman V,
Svoboda K, Looger LL (2009) Imaging neural activity in worms, flies and mice with improved GCaMP calcium indicators. Nat Methods 6:875881. CrossRef Medline

Tierney AJ (2001) Structure and function of invertebrate 5-HT receptors: a review. Comp Biochem Physiol A Mol Integr Physiol 128:791-804. CrossRef Medline

Vallés A, White K (1988) Serotonin-containing neurons in Drosophila melanogaster: development and distribution. J Comp Neurol 428:414-428. Medline

Vidal-Gadea A, Topper S, Young L, Crisp A, Kressin L, Elbel E, Maples T, Brauner M, Erbguth K, Axelrod A, Gottschalk A, Siegel D, PierceShimomura JT (2011) Caenorhabditis elegans selects distinct crawling and swimming gaits via dopamine and serotonin. Proc Natl Acad Sci U S A 108:17504-17509. CrossRef Medline

Wallén P, Buchanan JT, Grillner S, Hill RH, Christenson J, Hökfelt T (1989) Effects of 5-hydroxytryptamine on the afterhyperpolarization, spike frequency regulation, and oscillatory membrane properties in lamprey spinal cord neurons. J Neurophysiol 61:759-768. Medline

Xiang Y, Yuan Q, Vogt N, Looger LL, Jan LY, Jan YN (2010) Lightavoidance-mediating photoreceptors tile the Drosophila larval body wall. Nature 468:921-926. CrossRef Medline

Yang P, Shaver SA, Hilliker AJ, Sokolowski MB (2000) Abnormal turning behavior in Drosophila larvae. Identification and molecular analysis of scribbler (sbb). Genetics 155:1161-1174. Medline

Yuan Q, Lin F, Zheng X, Sehgal A (2005) Serotonin modulates circadian entrainment in Drosophila. Neuron 47:115-127. CrossRef Medline

Zhang YQ, Rodesch CK, Broadie K (2002) Living synaptic vesicle marker: synaptotagmin-GFP. Genesis 34:142-145. CrossRef Medline 